\title{
Simulation and Analyses of Multi-Body Separation in Launch Vehicle Staging Environment
}

\author{
Bandu N. Pamadi* \\ NASA Langley Research Center, Hampton, VA 23681-2199, USA \\ Nathaniel J. Hotchko ${ }^{\dagger}$ \\ Analytical Mechanics Associates, Hampton, VA, 23666-1307, USA \\ Jamshid Samareh, ${ }^{\star}$ Peter F. Covell ${ }^{\S}$ and Paul V. Tartabini ${ }^{* *}$ \\ NASA Langley Research Center, Hampton, VA 23681-2199, USA
}

\begin{abstract}
The development of methodologies, techniques, and tools for analysis and simulation of multi-body separation is critically needed for successful design and operation of next generation launch vehicles. As a part of this activity, ConSep simulation tool is being developed. ConSep is a generic MATLAB-based front-and-back-end to the commercially available ADAMS $^{\circledR}$ solver, an industry standard package for solving multi-body dynamic problems. This paper discusses the 3-body separation capability in ConSep and its application to the separation of the Shuttle Solid Rocket Boosters (SRBs) from the External Tank (ET) and the Orbiter. The results are compared with STS-1 flight data.
\end{abstract}

\section{Nomenclature}

A $\quad=$ axial location of SRB reference point in SSME plume coordinate system, $\mathrm{ft}$

$\mathrm{a}_{\mathrm{x}}, \mathrm{a}_{\mathrm{y}}, \mathrm{a}_{\mathrm{z}}=$ acceleration components along body axes (excluding components due to gravity) $\mathrm{ft} / \mathrm{sec}^{2}$

$C_{A} \quad=$ axial force coefficient

$\Delta C_{A} \quad=$ incremental (proximity) axial force coefficient

$\mathrm{C}_{1} \quad=$ rolling moment coefficient

$\Delta \mathrm{C}_{\mathrm{l}} \quad=$ incremental (proximity) rolling moment coefficient

$C_{m}=$ pitching moment coefficient

$\Delta C_{m} \quad=$ incremental (proximity) pitching moment coefficient

$C_{N} \quad=$ normal force coefficient

$\Delta C_{N} \quad=$ incremental (proximity) normal force coefficient

$C_{n} \quad=$ yawing moment coefficient

$\Delta C_{n} \quad=$ incremental (proximity) yawing moment coefficient

$\mathrm{C}_{\mathrm{Y}} \quad=$ side force coefficient

$\Delta \mathrm{C}_{\mathrm{Y}} \quad=$ incremental (proximity) side force coefficient

$\mathrm{F}_{x}, \mathrm{~F}_{y}, \mathrm{~F}_{z}=$ aerodynamic forces in axial, lateral and normal directions, $\mathrm{lb}$

$\mathrm{h}=$ altitude, $\mathrm{ft}$

$i \quad=$ variable index

$I_{x x}, I_{y y}, I_{z z}=$ moment of inertia about body $\mathrm{x}, \mathrm{y}, \mathrm{z}$ axes, slugs $\mathrm{ft}^{2}$

$\mathrm{I}_{\mathrm{xy}}, \mathrm{I}_{\mathrm{yz}}, \mathrm{I}_{\mathrm{zx}}=$ products of inertia about body $\mathrm{x}, \mathrm{y}, \mathrm{z}$ axes

$l_{\text {ref }} \quad=$ reference length, $\mathrm{ft}$

$\mathrm{L} \quad=$ rolling moment, lb-ft

$\mathrm{M} \quad=$ pitching moment, $\mathrm{lb}-\mathrm{ft}$

\footnotetext{
* Aerospace Engineer, Vehicle Analysis Branch, SACD, Associate Fellow AIAA.

${ }^{\dagger}$ Project Engineer, Member AIAA.

* Aerospace Engineer, Vehicle Analysis Branch, SACD, Associate Fellow AIAA.

$\S$ Aerospace Engineer, Vehicle Analysis Branch, SACD, Senior Member AIAA.

** Aerospace Engineer, Vehicle Analysis Branch, SACD, Member AIAA.
} 

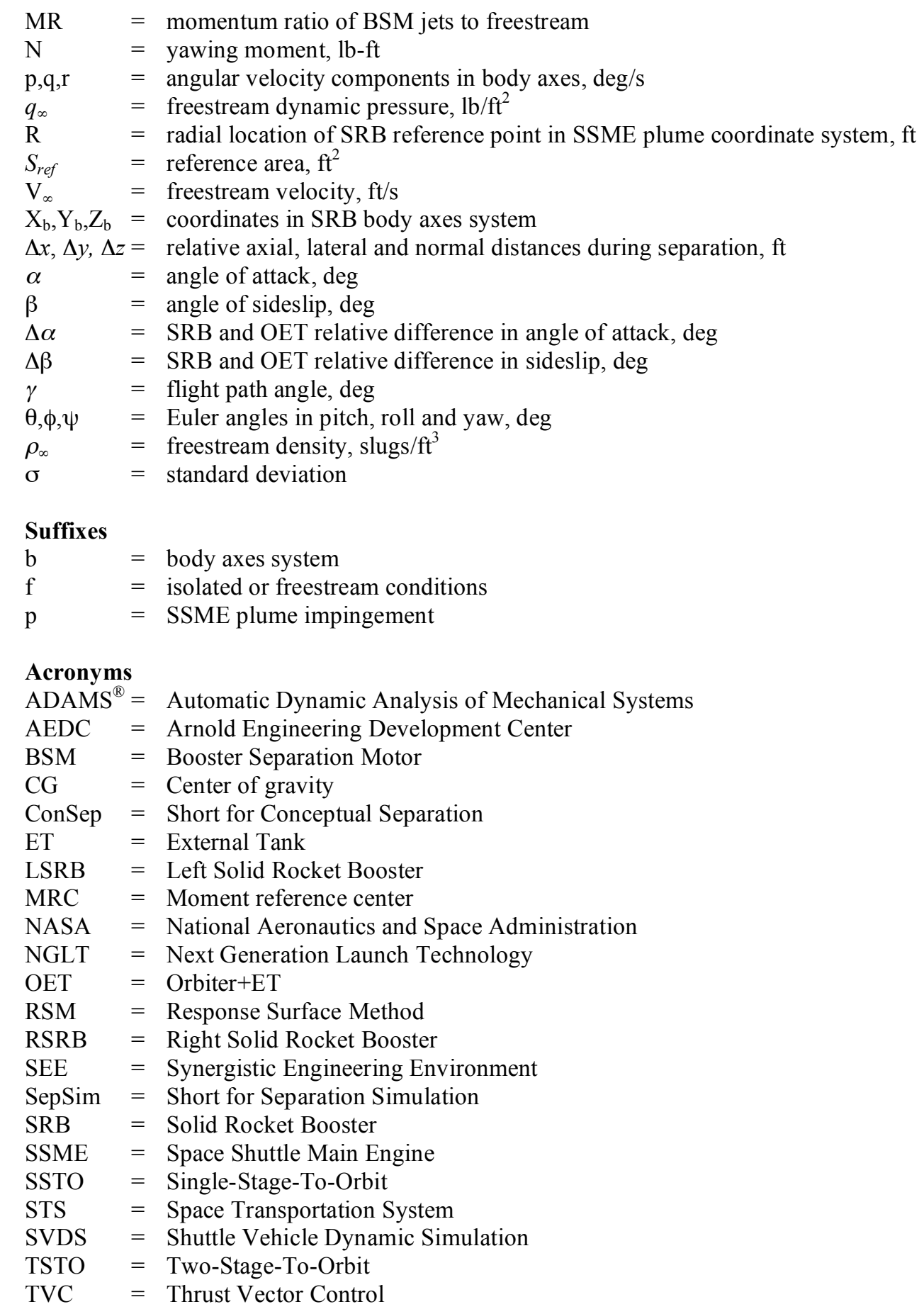

\section{Introduction}

$\mathrm{T}$ HE problem of multi-body separation within the atmosphere and in the launch vehicle staging environment is complex and challenging. One related problem that has received significant attention in the literature is that of store separation from aircraft. ${ }^{1}$ The aerodynamic characteristics of the relatively small sized store are influenced by the proximity of the aircraft, but the aerodynamic characteristics of the aircraft are virtually unaffected. A similar example is the separation of the X-15 research vehicle from the B-52 carrier aircraft. ${ }^{2}$ Here, the aerodynamic characteristics of the relatively smaller X-15 research vehicle are influenced by the proximity of the B-52 aircraft but not vice-versa. The other class of stage separation problem involves separation of two or more bodies of comparable 
sizes, where the aerodynamic characteristics of each vehicle are influenced by the proximity to other vehicle(s). However, in some cases the integrity of only one vehicle may be of importance, such as the staging of multi-stage expendable launch vehicles. The integrity of only the upper stages is of primary concern post separation. The expended stages need only to move away safely from the upper stages before eventual disintegration. For multi-stage reusable launch vehicles, the integrity of each stage is important post separation. A six degree-of-freedom, multibody separation code for hinged and/or linked lifting entry vehicles is presented in Ref. 3, and its application for the staging of Two-Stage-To-Orbit (TSTO) configuration featuring a delta-wing orbiter and a delta-wing booster is discussed in Ref. 4.

National Aeronautics and Space Administration (NASA) studies $^{5-9}$ on separation of multi-stage reusable launch vehicles date back to the early 1960s. These studies addressed the problem of separation of generic two-stage reusable launch vehicles. Recent NASA studies by Naftel et al ${ }^{10-12}$ consider Mach 3 staging of two winged vehicles. Interest in stage-separation research has come back when it was realized during early 2000 that technologies needed for the development of next generation reusable Single-Stage-To-Orbit (SSTO) vehicle are not yet available. Therefore, NASA's Next Generation Launch Technology (NGLT) Program identified stage separation as one of the critical technologies needed for successful development and operation of NASA's next generation multi-stage reusable launch vehicles. As a step towards developing this critically needed technology, NASA initiated a comprehensive stage separation tool development activity. ${ }^{13}$ A generic analysis and simulation tool called ConSep (short for Conceptual Separation) is being developed as a part of this activity. Application of ConSep for the simulation of twobody separation in a TSTO staging environment was discussed in References 14 and 15. In this paper, ConSep capability for three-body-separation problems is discussed with application to the separation of Shuttle Solid Rocket Boosters (SRB's) from Orbiter and External Tank (OET). The results are compared with STS-1 flight data and Boeing (previously Rockwell International) simulation. ${ }^{16-18}$ The Boeing SRB separation program is an SVDS (Shuttle Vehicle Dynamics Simulation) based three-body simulation that models the first four seconds of flight from separation to the end of OET attitude hold period and calculates the critical clearances throughout this time frame. The Boeing simulation ${ }^{16-18}$ was used for pre-flight certification and post-flight verification for STS-1. The analysis and simulation discussed in this paper are not an attempt for pre-flight certification or for post-flight verification of SRB separation from OET. Instead, the SRB separation from OET is used as a test and validation case for ConSep simulation of three-body separation in a launch vehicle staging environment.

\section{Vehicle Description}

The Space Shuttle is designed to launch a variety of payloads into (and/or retrieve from) Earth orbit. The Shuttle can deliver up to 65,000 lb for easterly launch from the Eastern Test Range at Kennedy Space Center (KSC) and up to 32,000 lb for a polar orbit launch from Western Test Range at Vandenburg Air Force Base. The Shuttle launch configuration consists of the Orbiter, External Tank (ET) and two SRBs. A schematic arrangement of the launch configuration is shown in Fig. 1. The SRBs burn in parallel with Space Shuttle Main Engines (SSMEs) and provide primary propulsion during the first stage of a Shuttle mission. Both SRBs and SSME engines feature thrust vector control (TVC).

The burn time of the SRBs is approximately two minutes. At burn out, the left and right SRBs separate simultaneously. The nominal staging of SRBs occurs from $150,000 \mathrm{ft}$ to $180,000 \mathrm{ft}$ altitude and Mach 3.75 to 4.0 . The SRB lateral and vertical separation is aided by a cluster of four booster separation motors (BSMs) located in the forward pods and another cluster of four BSMs on the aft skirts of each SRB. The BSMs provide lateral and normal acceleration of the SRBs away from the OET. The relative axial acceleration is achieved by the thrust from the SSMEs. After separation, the SRBs are decelerated by parachutes during their descent for splash down in the ocean approximately 141 nautical miles from the launch site. The SRBs are recovered and are refurbished for reuse. A schematic illustration of SRB separation and parachute descent and recovery is presented in Fig. 2.

The SRBs are attached to the ET at one point on the forward end and three points on the aft end. The forward attachment point is used to transfer the thrust loads from the SRB to the ET. The aft attachment points consist of three struts. At SRB separation, the bolts holding the forward and aft attachment points are severed. Simultaneously with severing of these bolts, the forward and aft BSMs on each SRB are fired to effect SRB separation from OET. The SRB separation is complex and is influenced by several factors. The OET cannot make lateral maneuver to aid separation because an SRB is coming off each side. Consequently, the OET is flown straight and in attitude-hold mode. Because the Orbiter engines are significantly above the OET center of gravity, they need to be canted for achieving moment balance for attitude-hold mode. As a result, the OET moves in z direction towards the SRBs. The BSM have sufficiently high thrust to move the SRBs away from the OET, resulting in a safe separation. 


\section{Development of SRB Separation Aerodynamic Database}

The Shuttle SRB separation aerodynamic database comprises of three components: (i) isolated aerodynamic database for each vehicle when they are in freestream conditions, (ii) proximity database for each vehicle, and (iii) SSME plume impingement database for each SRB to account for aerodynamic forces and moments due to SSME plume impingement. The isolated and plume impingement aerodynamic characteristics for left and right SRBs were assumed to be identical with proper sign adjustment.

The aerodynamic coefficients in proximity or stage separation environment depend on the relative locations and orientations of vehicles characterized by five separation variables $\Delta \alpha, \Delta \beta, \Delta x, \Delta y$ and $\Delta z$. The aerodynamic coefficients of left SRB (LSRB) and right SRB (RSRB) are assumed to be symmetrical with respect to the center body OET. For IA193 proximity wind tunnel tests, the separation variables $\Delta \alpha, \Delta \beta, \Delta x, \Delta y$ and $\Delta z$ are defined in Fig.3. Here, $\Delta x, \Delta y$ and $\Delta z$ are orthogonal displacements of SRB from its mated position. The variable $\Delta x$ is measured positive aft, $\Delta y$ positive outboards, and $\Delta z$ positive downward. For mated position, $\Delta \alpha=\Delta \beta=\Delta x=\Delta y=\Delta z=0$. The relative angles of attack and sideslip are defined as

$$
\begin{aligned}
& \Delta \alpha=\alpha(\mathrm{SRB})-\alpha(\mathrm{OET}) \\
& \Delta \beta=\beta(\mathrm{SRB})-\beta(\mathrm{OET})
\end{aligned}
$$

The dependence of proximity aerodynamic coefficients on the five separation variables $\Delta \alpha, \Delta \beta, \Delta x, \Delta y$ and $\Delta z$ is in addition to their usual dependence on Mach, $\alpha$ and $\beta$. Since the staging maneuvers last only for few seconds, the Mach number is usually assumed constant. With this assumption, the proximity coefficients depend on seven variables $\alpha, \beta, \Delta \alpha, \Delta \beta, \Delta x, \Delta \mathrm{y}$ and $\Delta z$. For SRB separation, there is an additional variable, the momentum ratio (MR) of the jets due to BSM separation motors, to account for the plume interference effects on proximity aerodynamic coefficients. Thus, the SRB separation proximity aerodynamic coefficients depend on eight variables.

The development of proximity aerodynamic database for the Shuttle SRB separation was a difficult and complex task, because the number of data points needed to populate a conventional database with eight independent variables would be unusually large. To get around this difficulty, the Shuttle program developed a novel method called "hyper cube" $^{, 19,21-23}$, which used far fewer data points. This method allowed data to be placed only along required separationpaths. For each selected $\Delta \mathrm{x}$, two 4-dimensional hypercubes were situated to cover all anticipated trajectory values in $\Delta y, \Delta z, \Delta \alpha$, and $\Delta \beta$. The inner hypercube was designed to include nominal separation trajectories with $3 \sigma$ dispersions, and the outer cube was designed to encompass all dispersions, including system failures. These hypercubes were not constrained to have parallel opposite sides. A sample trajectory through hypercube space is schematically illustrated in Fig. 4. Additional information on hypercube concept may be found in Ref. 19. Special wind tunnel tests, designated as IA193, were conducted at AEDC (Arnold Engineering Development Center) von Karman Gas Dynamics Facility supersonic Tunnel A at Mach 4.45 to develop the SRB separation proximity aerodynamic database in hypercube for$\mathrm{mat}^{23}$. Before these tests, NASA conducted several other wind tunnel tests, but the uncertainties associated with test data were believed to be too large ${ }^{23}$.

The IA193 test data set was obtained for plume-off $(\mathrm{MR}=0)$ and plume-on $(\mathrm{MR}=133.4$ and 222.3) conditions at Mach 4.45 using cold gas jet simulation. The IA193 proximity wind tunnel test data along with the hypercube interpolation reside in the Boeing SRB separation simulation software. However, the IA193 wind tunnel test data was available for this study, but not the hypercube interpolator. Hence an alternative approach based on Response Surface $\operatorname{Method~}^{24}$ (RSM) was used to generate the proximity aerodynamic database, because RSM is suited for cases where data is too sparse for conventional eight-variable interpolation methods. The RSM approach is based on building functional representation of complex multi-dimensional data set using polynomial fits. For RSM representation of IA193 test data, quadratic polynomials were used. The RSM fit errors were estimated using the methods discussed in Ref. 24. The isolated aerodynamic databases for OET and SRB were generated for Mach 4.45 using the data provided in Shuttle Performance Enhancement Design Data Book. ${ }^{19}$ The RSM approach was also used for development of isolated aerodynamic database of OET and SRBs.

The aerodynamic forces and moments are defined as follows:

$$
\begin{aligned}
& F_{x}=\frac{1}{2} \rho_{\infty} V_{\infty}{ }^{2} S_{r e f} C_{A}+F_{x, p} \\
& F_{y}=\frac{1}{2} \rho_{\infty} V_{\infty}{ }^{2} S_{r e f} C_{Y}+F_{y, p}
\end{aligned}
$$




$$
\begin{gathered}
F_{z}=\frac{1}{2} \rho_{\infty} V_{\infty}{ }^{2} S_{r e f} C_{N}+F_{z, p} \\
L=\frac{1}{2} \rho_{\infty} V_{\infty}{ }^{2} S_{r e f} l_{r e f} C_{l}+L_{p} \\
M=\frac{1}{2} \rho_{\infty} V_{\infty}{ }^{2} S_{r e f} l_{r e f} C_{m}+M_{p} \\
N=\frac{1}{2} \rho_{\infty} V_{\infty}{ }^{2} S_{r e f} l_{r e f} C_{n}+N_{p}
\end{gathered}
$$

where $S_{r e f}$ is the reference (wing) area, $l_{\text {ref }}$ is the reference (body) length, and the suffix "p" denotes aerodynamic forces and moments due to SSME plume impingement. Note that $l_{\text {ref }}$ is used as reference length for both longitudinal and lateral/directional coefficients. For Space Shuttle aerodynamic data, $\mathrm{S}_{\mathrm{ref}}=2690.0 \mathrm{ft}^{2}$ and $l_{\text {ref }}=107.52 \mathrm{ft}$. The aerodynamic coefficients in proximity are functions of eight variables, $\alpha, \beta, \Delta \alpha, \Delta \beta, \Delta x, \Delta y, \Delta z$, and MR. The total coefficients are expressed as a sum of isolated and proximity incremental coefficients (with respect to isolated conditions) as follows:

$$
\begin{gathered}
C_{A, i}=C_{A f, i}(\alpha, \beta)+\Delta C_{A, i}(\alpha, \beta, \Delta \alpha, \Delta \beta, \Delta x, \Delta y, \Delta z, M R) \\
C_{N, i}=C_{N f, i}(\alpha, \beta)+\Delta C_{N, i}(\alpha, \beta, \Delta \alpha, \Delta \beta, \Delta x, \Delta y, \Delta z, M R) \\
C_{Y, i}=C_{Y f, i}(\alpha, \beta)+\Delta C_{Y, i}(\alpha, \beta, \Delta \alpha, \Delta \beta, \Delta x, \Delta y, \Delta z, M R) \\
C_{l, i}=C_{l f, i}(\alpha, \beta)+\Delta C_{l, i}(\alpha, \beta, \Delta \alpha, \Delta \beta, \Delta x, \Delta y, \Delta z, M R) \\
C_{m, i}=C_{m f, i}(\alpha, \beta)+\Delta C_{m, i}(\alpha, \beta, \Delta \alpha, \Delta \beta, \Delta x, \Delta y, \Delta z, M R) \\
C_{n, i}=C_{n f, i}(\alpha, \beta)+\Delta C_{n, i}(\alpha, \beta, \Delta \alpha, \Delta \beta, \Delta x, \Delta y, \Delta z, M R)
\end{gathered}
$$

Here, the suffix "f" denotes freestream or isolated conditions, " $i$ " denotes the vehicle number, $i=1$ for left SRB, $i=2$ for $\mathrm{OET}$, and $i=3$ for right SRB. The incremental coefficients like $\Delta C_{A, i}$ denote increments due to proximity effects with respect to isolated or freestream conditions. In other words, when the vehicles move out of the proximity range and are essentially in isolated or freestream (no interference) conditions, these incremental coefficients are equal to zero.

The range of variables of IA193 test data (both inner and outer hypercubes) is summarized in Table I. The IA193 test data does not include the proximity incremental axial force coefficients for OET and SRBs, as well as incremental rolling moment coefficient for SRBs. Hence, in this study $\Delta C_{A, i}=0, i=1,2,3$ and $\Delta C_{l, i}=0$, $i=1$ and 3 . Also, for SRBs, the isolated rolling moment coefficient was assumed equal to zero. ${ }^{19}$

The proximity wind tunnel test data IA193 does not cover sufficiently large values of $\Delta \mathrm{x}, \Delta \mathrm{y}$ and $\Delta \mathrm{z}$ so that the vehicles are in freestream conditions (incremental coefficients equal to zero). In view of this, for every slice of the eight dimensional data set, an outer polygon with sides are equal to 1.5 times the respective sides of the inner polygon in which proximity data is defined, where the aerodynamic coefficients transition from proximity database to freestream conditions. Thus, on and outside the outer polygon, the incremental coefficients are zero, and the aerodynamic coefficients assume their freestream values. Inside the inner polygon, the incremental coefficients assume their proximity values, and in the transition region, linear weighted interpolation method was used.

The RSM representation of isolated OET data is shown in Fig. 5. The isolated OET data covers $\alpha$ and $\beta$ range from $-15 \mathrm{deg}$ to $+15 \mathrm{deg}$. The RSM representation of isolated SRB data is shown in Fig. 6 and covers $\alpha$ and $\beta$ range from 0 to $+80 \mathrm{deg}$. The aerodynamic coefficients for $\alpha$ or $\beta$ from -80 deg to 0 are obtained by reflection of the data on the negative side with proper adjustment of signs. 
Since proximity aerodynamic coefficients are functions of eight separation variables, it is difficult plot these coefficients to show variations with all eight variables at the same time. However, to illustrate the complex nature of the proximity aerodynamic coefficients, the RSM representations for $\alpha=0, \beta=0, \Delta \alpha=0, \Delta \beta=0, \mathrm{MR}=222.3$ (plume on) for various combinations of $\Delta \mathrm{x}, \Delta \mathrm{y}$ and $\Delta \mathrm{z}$ are presented in Figs. 7-9 for OET and for SRB in Figs. 10-12. Also included in these figures are the inner and the outer polygons. The incremental coefficients display significant variations inside the inner polygon and transition smoothly to zero on the outer polygon.

The SSME plume impingement aerodynamic data is available ${ }^{19}$ in the form of incremental forces and moments, which depend on four variables A, R, $\theta$, and $\psi$ as shown in Fig. 13. Here, A and R are the axial and radial locations of the SRB reference point in SSME plume coordinate system, and $\theta$ and $\psi$ are the pitch and yaw angles as shown in Fig. 13. The plume impingement incremental forces and moments are to be directly added to the proximity forces and moments as indicated in Eqs. (1)-(6). The plume impingement data ${ }^{19}$ covers axial distances only up to $1700 \mathrm{in}$. However, in this study, it was observed that plume impingement occurs for axial distances greater than $1700 \mathrm{in}$. In view of this, and for lack of a better alternative, the available data ${ }^{19}$ were extended up to 3000 in consistent with spread/decay of the SSME plume. The RSM approach was used to develop SSME plume impingement database for SRBs.

\section{Simulation of Shuttle SRB Separation}

The simulation of SRB separation from OET was done using ADAMS ${ }^{\mathbb{B}}$ (Automatic Dynamic Analysis of Mechanical Systems) solver, an industry standard package for solving multi-body dynamic problems. ${ }^{25}$ The user does not have to input the governing equations of motion to $\mathrm{ADAMS}^{\mathbb{B}}$ for vehicle motion during stage separation, but user needs to define inertial and body fixed reference coordinates for each vehicle and provides mathematical models of the aerodynamic and other external forces/moments acting on each of the three vehicles during stage separation. ADAMS $^{\mathbb{B}}$ assembles coupled/constrained equations of motion for each vehicle based on user inputs and generates solutions to those equations as per user requests. To simplify the process of using ADAMS ${ }^{\circledR}$ for solving stage separation problems, NASA Langley has developed a MATLAB-based front-and-back-end, called ConSep, to ADAMS ${ }^{\circledR}$ solver. ConSep derives its heritage from SepSim (short for Separation Simulation), a front-and-back-end to ADAMS $^{\circledR}$ solver that was used to simulate X-43A (Hyper-X) stage separation event. An independent verification of the ADAMS ${ }^{\circledR}$ predictions of the X-43A stage separation was conducted using POST (Program to Optimize Simulated Trajectories), and the two results were found to be in close agreement ${ }^{26}$. This exercise confirmed that ADAMS $^{\circledR}$ sets up and solves the equations of motion for stage separation problems in an acceptable manner.

ConSep allows the user to setup multi-body separation problems in a simple manner. It converts the user inputs into the model specifications used by ADAMS ${ }^{\circledR}$, initiates ADAMS $^{\circledR}$ solver, and post-processes the ADAMS ${ }^{\circledR}$ output to express the simulation results in a convenient form. ConSep is designed to allow the user to link aerodynamic mathematical models, aerodynamic data tables, interpolation routines, model vehicle attachment points/joints, separation forces due to reaction jets, spring or piston type devices, closed-loop proportional and derivative (PD) control, actuator dynamics, atmospheric winds, engine gimbals, thrust time histories and thrust vectoring etc. to ADAMS ${ }^{\circledR}$ solver. ConSep is also designed to permit the user to study the effect of variations in selected input parameters and perform Monte Carlo studies. The main advantage of ConSep is that user does not have to be trained in ADAMS ${ }^{\circledR}$ for solving stage separation problems. Additional information on ConSep is available in Ref. 27.

The inputs to ConSep/ADAMS ${ }^{\circledR}$ simulation of SRB separation from OET were as follows: definition of bodyfixed coordinate system for each vehicle in relation to the selected ground-fixed (inertial) system (North-EastDown) via Euler angles, mass, inertia, center of gravity of each vehicle in respective body-fixed coordinate system, initial altitude, initial velocity, initial flight path angle, initial angle of attack of each vehicle, mathematical model of aerodynamic forces and moments in proximity (RSM models), transition, isolated or freestream conditions, location of the moment reference point for each vehicle, magnitude and direction of net resultant of forward and aft BSM thrust, magnitude and direction of resultant SSME thrust, time/event for the release of front and aft joints, time for starting and stopping the integration of equations of motion, step size and accuracy of integration.

The nominal mass and inertia at SRB separation for STS-1 are given in Table II (from Ref. 17). The center of gravity locations are shown in Fig. 14 and the aerodynamic moment reference points in Fig. 15. Also shown in Fig. 14 is the assumed location and orientation of the net resultant thrust from the three SSMEs. The thrust produced by each SSME was assumed to be equal to $467,000 \mathrm{lb}$, and that the net thrust was assumed to pass through the center of gravity of the OET to reflect the "attitude hold" mode of the OET during SRB separation. The canting angle of the net thrust was estimated to be $13.35 \mathrm{deg}$ as shown in Fig. 14.

The flight parameters at SRB separation for STS-1 are presented in Table III. The SRB propulsion characteristics for STS-1 are given in Table IV. The thrust tail-off from initiation of separation $(t=0)$ is shown in Fig. 16. The nominal BSM locations are presented in Table V. Each of these BSM jets are nominally inclined 40 deg in pitch 
plane and 20 deg in roll-yaw plane as shown in Fig. 17. The variations in BSM cluster orientations from their nominal values and the cluster propulsion characteristics for STS-1 are given in Table VI. In ConSep, thrusts produced by forward and aft BSM clusters were implemented as one net force on each SRB acting for an average period as indicated in Table VI. The BSM jet momentum ratio (MR) was evaluated using the data given in Fig. 18 and the data in Table IV. The MR was found to be in excess of 730 . However, the proximity aero data in IA193 data goes only up to MR $=222.3$. Therefore, using the "no extrapolation" approach recommended in Ref. 19, the IA193 test data for $\mathrm{MR}=222.3$ were used in this simulation for the duration when BSMs were on.

The parameters used in ConSep simulation are listed in Table VII. The estimated uncertainties in RSM based proximity aerodynamic coefficients for $\mathrm{MR}=0$ and 222.3 are shown in Fig. 19 and compared with those based on hypercube approach. The RSM uncertainties represent the curve fit errors to the IA193 proximity data for MR $=0$ and 222.3. These do not include wind tunnel measurement uncertainties and other sources of uncertainties included in hypercube uncertainties. Hence, the hypercube uncertainties are larger than the RSM uncertainties. It may be noted that the hypercube uncertainties were evaluated by conducting special wind tunnel test along a typical SRB separation trajectory. ${ }^{23}$

The effect of forces in the attach hardware at SRB release were not included in ConSep simulation. Also, various clearances between specified points on the OET and SRBs as done in SVDS simulation ${ }^{16,17,18}$ were not included in ConSep simulations.

For STS-1 flight data, the separation distances $\Delta \mathrm{x}, \Delta \mathrm{y}$ and $\Delta \mathrm{z}$ are defined with respect to the center of gravity of OET and SRBs as shown in Fig. 20.

The results of ConSep simulation of the SRB separation for STS-1 are presented in Figs. 21 to 29 along with flight data and SVDS simulation results. ${ }^{16,17,18}$ ConSep simulation shows that SRBs separate safely from OET. The predicted relative locations of the vehicles during separation are in good agreement with flight data (Fig.21). However, the lateral separation distance $\Delta y$ differs slightly from the flight data. The component accelerations for OET, left and right SRBs are in good agreement with flight data (Figs. 22 to 24). However, the component angular velocities for OET, left and right SRBs show differences from flight data (Figs. 25 to 27). The gimbal angles of each of the three SSME are continuously varied during separation in STS-1, and these variations were not modeled in ConSep. Further, the rolling moment coefficient for SRB was assumed zero. It is also possible that these factors and the strut forces at release not included in ConSep contribute to these differences. The angles of attack and sideslip of the orbiter are steady during separation, but the SRBs show steady build up as shown in Figs. 28 and 29.

The Synergistic Engineering Environment ${ }^{28}$ (SEE) was used to create animations of the staging maneuvers. The SEE used the geometry models of the SRBs, OET and the ConSep output to generate these animations. The geometrical shape of the SSME engine plume was modeled using the data on jet boundary given in Refs. 17 and 20. The plume shapes were included in the geometry model of the Orbiter and SRBs. Some sample snap shots of SEE animation are presented in Fig. 30. It is interesting to note that SSME plume impinges on SRBs for $t>3.0 \mathrm{sec}$ justifying the inclusion of incremental forces and moments on SRBs due to SSME plume impingement.

\section{Concluding Remarks}

The capability of NASA Langley developed, generic multi-body, six-degree-of-freedom separation tool "ConSep" was discussed with application to Shuttle SRB separation for STS-1 flight as a test/validation case. The RSM approach was used to develop aerodynamic databases in functional form for isolated and proximity aerodynamic coefficients. The results of ConSep simulation are in good agreement with STS-1 flight data. This exercise indicates that ConSep can satisfactorily simulate multi-body separations in launch vehicle staging environment. However, some differences between ConSep and STS-1 flight data exist, and these differences need to be resolved by improved modeling of propulsion units with multiple TVC engines and including the strut forces at release.

\section{Acknowledgments}

The authors would like to acknowledge Johann Hoff for providing SRB Separation documentation and generous help during the course of this study. The authors also acknowledge Paul Romere, Steven Munday, Phil Robinson, Carlos Ortiz, Peter Parker, Scott Angster, David Bose, Lawrence Taylor, III, and Anthony Guinta for help and assistance during this study. 


\section{References}

${ }^{1}$ Dillenius, M.F.E., Perkins, S.C., and Nixon, D., Pylon Carriage and Separation of Stores, AIAA Progress in Astronautics and Aeronautics: Tactical Missile Aerodynamics-General Topics, M.J.Hemsch, ed., Vol. 141, 1992.

${ }^{2}$ Taylor, R.T., and Alford, W.J., Jr., A wind tunnel investigation of the carry loads and mutual interference effects of 1/40-scale models of the X-15 and B-52 airplanes in combination, NASA TM X-184, December 1959.

${ }^{3}$ Hurley, M.J., "Digital Program P5255, A Six-Degree, Multiple Body Separation Simulation for Hinged and/or Linked Lifting Entry Vehicles", Vols. I and II, GDC-ERR-1377, December 1969, Convair Aerospace Division of General Dynamics, San Diego, CA.

${ }^{4}$ Hurley, M.J., Carrie, G.W., "Stage Separation of Parallel-Staged Shuttle Vehicles: A Capability Assessment," Journal of Spacecraft, Vol. 9, No. 10, October 1972, pp. 764-771.

${ }^{5}$ Decker, J.P., and Wilhite, A.W., Technology and Methodology of Separating Two Similar Size Aerospace Vehicles Within the Atmosphere. AIAA Paper 1975-29, Jan. 1975.

${ }^{6}$ Decker, J.P., Experimental Aerodynamics and Analysis of the Stage Separation of Reusable Launch Vehicles. NASA-SP-148, January 1967.

${ }^{7}$ Decker, J.P., and Gera, J., An Exploratory Study of Parallel-Stage Separation of Reusable Launch Vehicles. NASA TN D-4765, October 1968.

${ }^{8}$ Decker, J.P., Aerodynamic Interference Effects Caused by Parallel-Staged Simple Aerodynamic Configuration at Mach Numbers of 3 and 6. NASA TN D-5379, Aug. 1969.

${ }^{9}$ Wilhite, A.W., Analysis of Separation of the Space Shuttle Orbiter from a Large Transport Airplane. NASA TM X-3492, June 1977.

${ }^{10}$ Naftel, J.C., and Wilhite, A.W., Analysis of Separation of a Two-Stage Winged Launch Vehicle. AIAA Paper 86-0195, Jan. 1986.

${ }^{11}$ Naftel, J.C., and Powell, R.W., Aerodynamic Separation and Glideback of a Mach 3 Staged Orbiter. AIAA Paper 90-0223, Jan. 1990.

${ }^{12}$ Naftel, J.C., and Powell, R.W., Analysis of the Staging Maneuver and Booster Glideback Guidance for a TwoStaged, Winged, Fully Reusable Launch Vehicle. NASA TP-3335, 1993.

${ }^{13}$ Murphy, K.J., Buning, P.G., Pamadi, B.N., Scallion, W.I., and Jones, K.M.; Status of Stage Separation Tool Development for Next Generation Launch Vehicle Technologies. AIAA Paper 2004-2595.

${ }^{14}$ Pamadi, B.N., Neirynck, T.A., Covell, P.F., Hotchko, N.J., and Bose, D.M., Simulation and Analyses of Staging Maneuvers of Next Generation Reusable Launch Vehicles, AIAA Paper 2004-5185.

${ }^{15}$ Pamadi, B.N., Neirynck, T.A., Hotchko, N.J., Tartabini, P.V., Scallion, W.I., Murphy, K.J., and Covell, P. F., Simulation and Analyses of Stage Separation of Two-Stage Reusable Launch Vehicles, AIAA Paper 2005-3247.

${ }^{16}$ Elchert, K.C., Space Shuttle Solid Rocket Booster Separation System, AIAA Paper 82-39006.

${ }^{17}$ STS 81-0277 "Space Shuttle System Engineering Analysis Report, SRB Separation System Verification," Rockwell International, March 1981.

${ }^{18}$ STS 82-0570, "Space Shuttle System SRB Separation Verification For Operations," Rockwell International, November 1982.

${ }^{19}$ Boeing, Performance Enhancement Operational Aerodynamic Design Data Book, Launch Vehicle Aerodynamic Data, RSS98D0313, January 28, 1999.

20 “Space Shuttle SRB Separation Data Book," SSD97D0385, Boeing, September 30, 1997.

${ }^{21}$ Crosby, W.A., and Lanham, D.L., Integrated Aerodynamic Tests Of The Space Shuttle Vehicle During Solid Rocket Booster Separation at Mach 4.5 (IA 193), AEDC-TSR-82-V15, June 1982.

${ }^{22}$ Craig, M.K., and Dresser, H.S., Shuttle Booster Separation Aerodynamics", N84 10123

23 "SRB Separation Wind Tunnel Test IA-193 Final Report" (EMS 290-200-335), No, SAS/Aero/83-073, Rockwell International, February, 1, 1983.

${ }^{24}$ Myers, R.H., and Montgomery, D.C., Response Surface Methodology: Process and Product in Optimization Using Design of Experiments, Willey, New York, 1995.

25 "Using ADAMS/Solver", Mechanical Dynamics Inc., 1999.

${ }^{26}$ Tartabini, P.V., Bose, D.M., McMinn, J.D., Martin, J.G., and Stovers, B.K., Hyper-X Stage Separation Trajectory Validation Studies, AIAA Paper 2003-5819.

${ }^{27}$ Bose D.M., and Hotchko, N., Conceptual Level Stage Separation Simulation (ConSep)-Version 1.4 Beta User's Guide, Report No. 04-41, Analytical Mechanics Associates, Hampton, VA, December 2004.

${ }^{28}$ Angster, S., Synergistic Engineering Environment Build II User's Guide Revision E, AMA Report No. 03-31, Analytical Mechanics Associates, Hampton, VA, August 2003. 
Table I (a). Range of Independent Variables in IA193 Proximity Hypercube-Format Test Data, Plume-off $(\mathrm{MR}=\mathbf{0})$

\begin{tabular}{ccccccc}
\hline \hline $\boldsymbol{\alpha}$ (deg) & $\boldsymbol{\beta}$ (deg) & $\boldsymbol{\Delta} \mathbf{x}$ (inches) & $\boldsymbol{\Delta} \mathbf{y}$ (inches) & $\boldsymbol{\Delta z}$ (inches) & $\Delta \boldsymbol{\alpha}(\mathrm{deg})$ & $\Delta \boldsymbol{\beta}(\mathrm{deg})$ \\
\hline-10 to 10 & -10 to 10 & 0 & 0 & 0 & 0 & 0 \\
-10 to 10 & -10 to 10 & 100 & 10 to 110 & 40 to 250 & -7.0 to 0 & -5.5 to 1.0 \\
-10 to 10 & -10 to 10 & 300 & 30 to 260 & 40 to 550 & -17.0 to 0 & -15.0 to 2.0 \\
-10 to 10 & -10 to 10 & 600 & 90 to 510 & 140 to 800 & -30.0 to 0 & -20.0 to 3.0 \\
-10 to 10 & -10 to 10 & 1100 & 100 to 700 & 180 to 900 & -33.0 to 0 & -20.0 to 3.0 \\
-10 to 10 & -10 to 10 & 1700 & 200 to 800 & 300 to 1000 & -34.0 to -5.0 & -20.0 to 8.0 \\
\hline \hline
\end{tabular}

Table I (b). Range of Independent Variables in IA193 Proximity Hypercube-Format Test Data, Plume-on (MR = 133.4, 222.3)

\begin{tabular}{ccccccc}
\hline \hline $\boldsymbol{\alpha}$ (deg) & $\boldsymbol{\beta}$ (deg) & $\boldsymbol{\Delta} \mathbf{x}$ (inches) & $\boldsymbol{\Delta} \mathbf{y}$ (inches) & $\boldsymbol{\Delta} \mathbf{z}$ (inches) & $\boldsymbol{\Delta} \boldsymbol{\alpha}(\mathbf{d e g})$ & $\Delta \boldsymbol{\beta}(\mathbf{d e g})$ \\
\hline-10 to 10 & -10 to 10 & 0 & 0 & 0 & 0 & 0 \\
-10 to 10 & -10 to 10 & 100 & 10 to 110 & 40 to 250 & -7 to 0 & -5.5 to 1.0 \\
-10 to 10 & -10 to 10 & 200 & 20 to 150 & 60 to 280 & -7 to 0 & -6.5 to 0.5 \\
\hline \hline
\end{tabular}

Table II. Vehicle Mass and Inertia Properties at Staging

\begin{tabular}{cccccccc}
\hline \hline Configuration & $\begin{array}{c}\text { Weight, } \\
\mathbf{l b}\end{array}$ & $\begin{array}{c}\text { Ixx, } \\
\text { Slugs ft }\end{array}$ & $\begin{array}{c}\text { Iyy, } \\
\text { Slugs ft }\end{array}$ & $\begin{array}{c}\text { Izz, } \\
\text { Slugs ft }^{2}\end{array}$ & $\begin{array}{c}\text { Ixy, } \\
\text { Slugs ft }^{2}\end{array}$ & $\begin{array}{c}\text { Iyz, } \\
\text { Slugs ft }^{2}\end{array}$ & $\begin{array}{c}\mathbf{I x z}^{2}, \\
\text { Slugs ft }^{2}\end{array}$ \\
\hline \multirow{2}{*}{ Orbiter/+ET } & $1,473,332$ & $5,241,320$ & $83,826,248$ & $80,221,300$ & $124,263.3$ & $12,024,025$. & $35,820.9$ \\
& & & & & & 0 & \\
Left SRB & 180,881 & 192,915 & $11,348,219$ & $11,351,222$ & $-27,923.0$ & $7,508.0$ & 688.0 \\
Right SRB & 181,833 & 241,702 & $11,463,621$ & $11,466,376$ & $24,651.0$ & $9,670.0$ & $-1,043.0$ \\
\hline \hline
\end{tabular}


Table III. Flight Parameters at SRB Separation for STS-1

\begin{tabular}{lc}
\hline \multicolumn{1}{c}{ Parameter } & Value \\
\hline Altitude, ft & 173,857 \\
Velocity, ft/sec & 4112.0 \\
Mach Number & 3.877 \\
Dynamic Pressure, lb/ft ${ }^{2}$ & 12.83 \\
Angle of Attack, deg & 3.0 \\
Sideslip, deg & 0.75 \\
Flight Path Angle, deg & 36.966 \\
Body Roll Rate, deg/sec & -0.3 \\
Body Pitch Rate, deg/sec & 0.4 \\
Body Yaw Rate, deg/sec & 0 \\
\hline \hline
\end{tabular}

Table IV. SRB Propulsion Characteristics at Separation, STS-1

\begin{tabular}{lcc}
\hline \multicolumn{1}{c}{ Parameter } & Left SRB & Right SRB \\
\hline Propellant Mean Bulk & $\mathbf{6 8 . 0}$ & $\mathbf{6 8 . 0}$ \\
Temperature (PMBT), deg F & $18,297.0$ & $24,049.0$ \\
Thrust, lb & 0.042 & 0.064 \\
Pitch gimbal angle, deg & -0.679 & 0.672 \\
Yaw gimbal angle,deg &
\end{tabular}

Table V. BSM Nominal Locations

\begin{tabular}{ccccc}
\hline \hline BSM No & Type & Xb (inches) & Yb (inches) & Zb (inches) \\
\hline 1 & Forward & 290.230 & 19.625 & 26.616 \\
2 & Forward & 303.888 & 20.811 & 30.863 \\
3 & Forward & 290.23 & 2.351 & 32.772 \\
4 & Forward & 303.888 & 3.896 & 37.019 \\
5 & Aft & 1886.722 & 59.755 & 82.245 \\
6 & Aft & 1886.722 & 40.573 & 93.418 \\
7 & Aft & 1886.722 & 28.357 & 97.864 \\
8 & Aft & 1886.722 & 15.548 & 100.682 \\
\hline \hline
\end{tabular}


Table VI. BSM-Cluster Propulsion Characteristics at Separation, STS-1

\begin{tabular}{ccccc}
\hline \hline Parameter & $\begin{array}{c}\text { Left SRB } \\
\text { Forward }\end{array}$ & $\begin{array}{c}\text { Left SRB } \\
\text { Aft }\end{array}$ & $\begin{array}{c}\text { Right SRB } \\
\text { Forward }\end{array}$ & $\begin{array}{c}\text { Right SRB } \\
\text { Aft }\end{array}$ \\
\hline$\Delta \phi$, deg & 0.04 & 0.113 & 0.18 & 0.05 \\
$\Delta \theta$, deg & 0 & 0.10 & 0.14 & 0.071 \\
$\begin{array}{c}\text { Maximum Chamber } \\
\text { Pressure, psia }\end{array}$ & 1844.9 & 1832.1 & 1854.7 & 1848.4 \\
$\begin{array}{c}\text { Maximum Thrust, lb } \\
\text { Average Thrust, l lb }\end{array}$ & $92,096.0$ & $91,457.0$ & $92,587.0$ & $92,272.0$ \\
Average Duration, sec & 89,620 & 88,162 & 90,776 & 90,884 \\
\hline \hline
\end{tabular}

Table VII. ConSep Simulation Parameters

\begin{tabular}{cc}
\hline \hline Parameter & Value \\
\hline Simulation time, sec & 4.0 \\
Integration step size, sec & 0.01 \\
Front Joint Release, sec & 0.02 \\
Aft-Joint Release, sec & 0.02 \\
\hline \hline
\end{tabular}



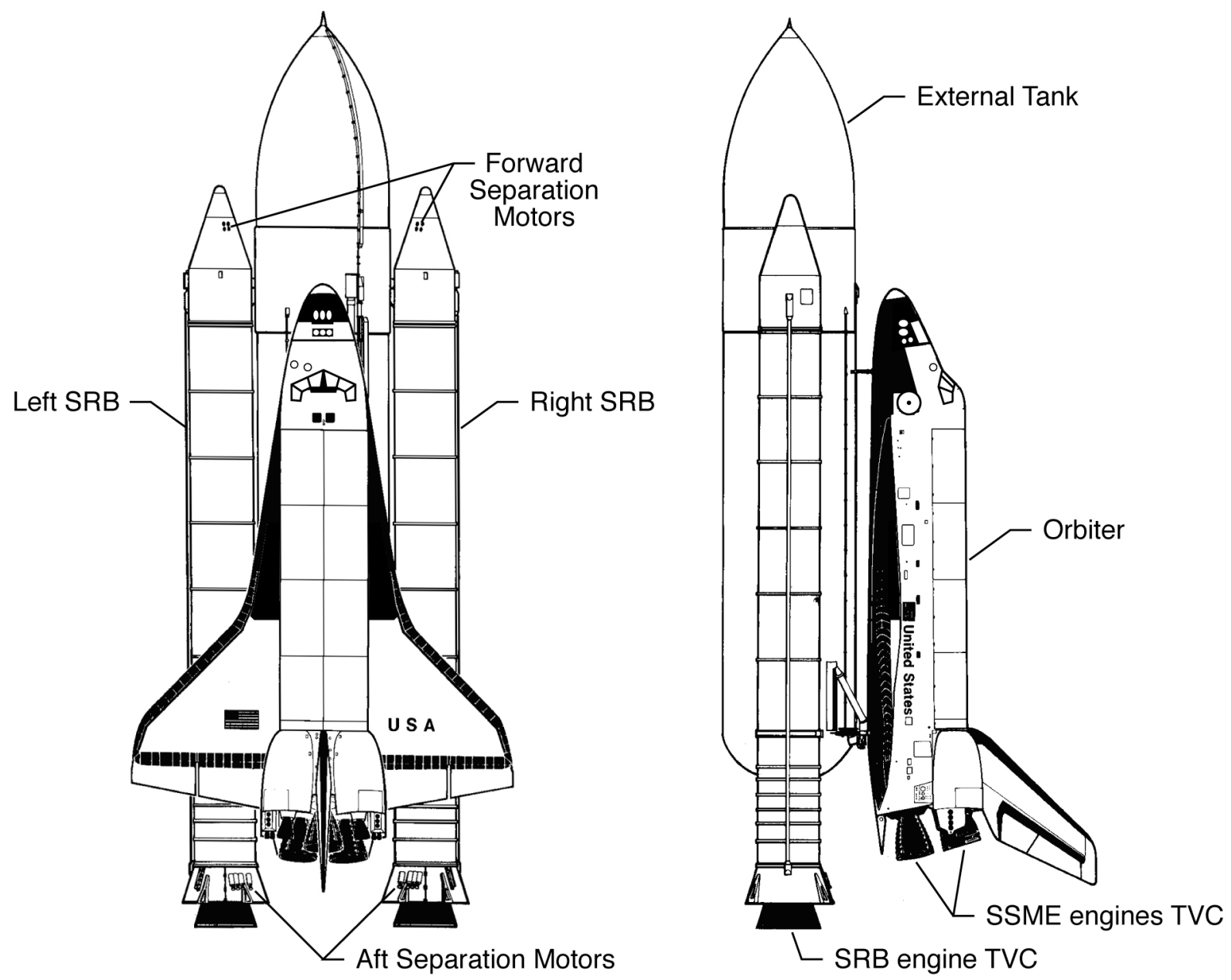

Figure 1. Space Shuttle vehicle configuration. (Ref. 20). 


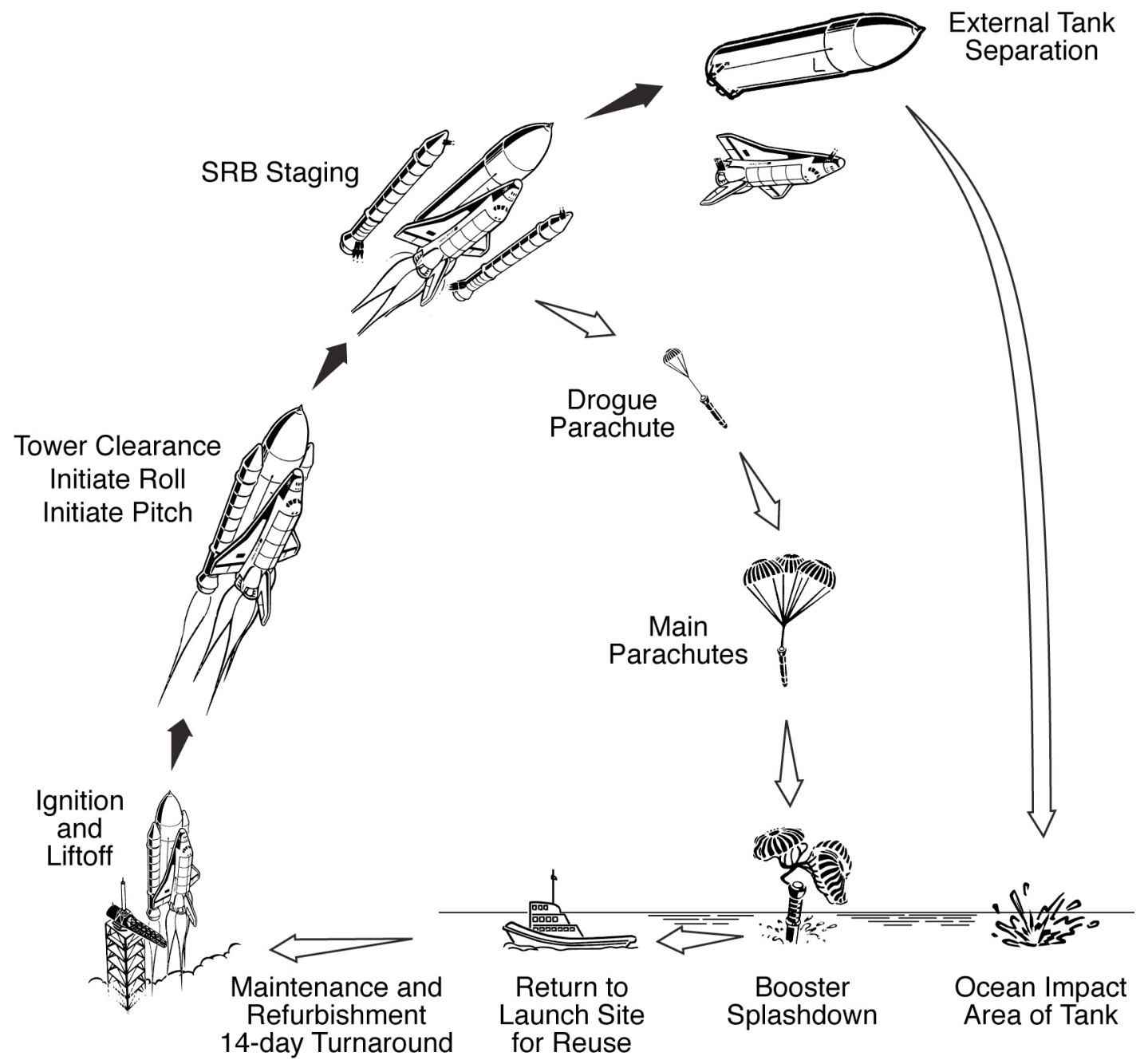

Figure 2. Schematic illustration of Space Shuttle staging events. 


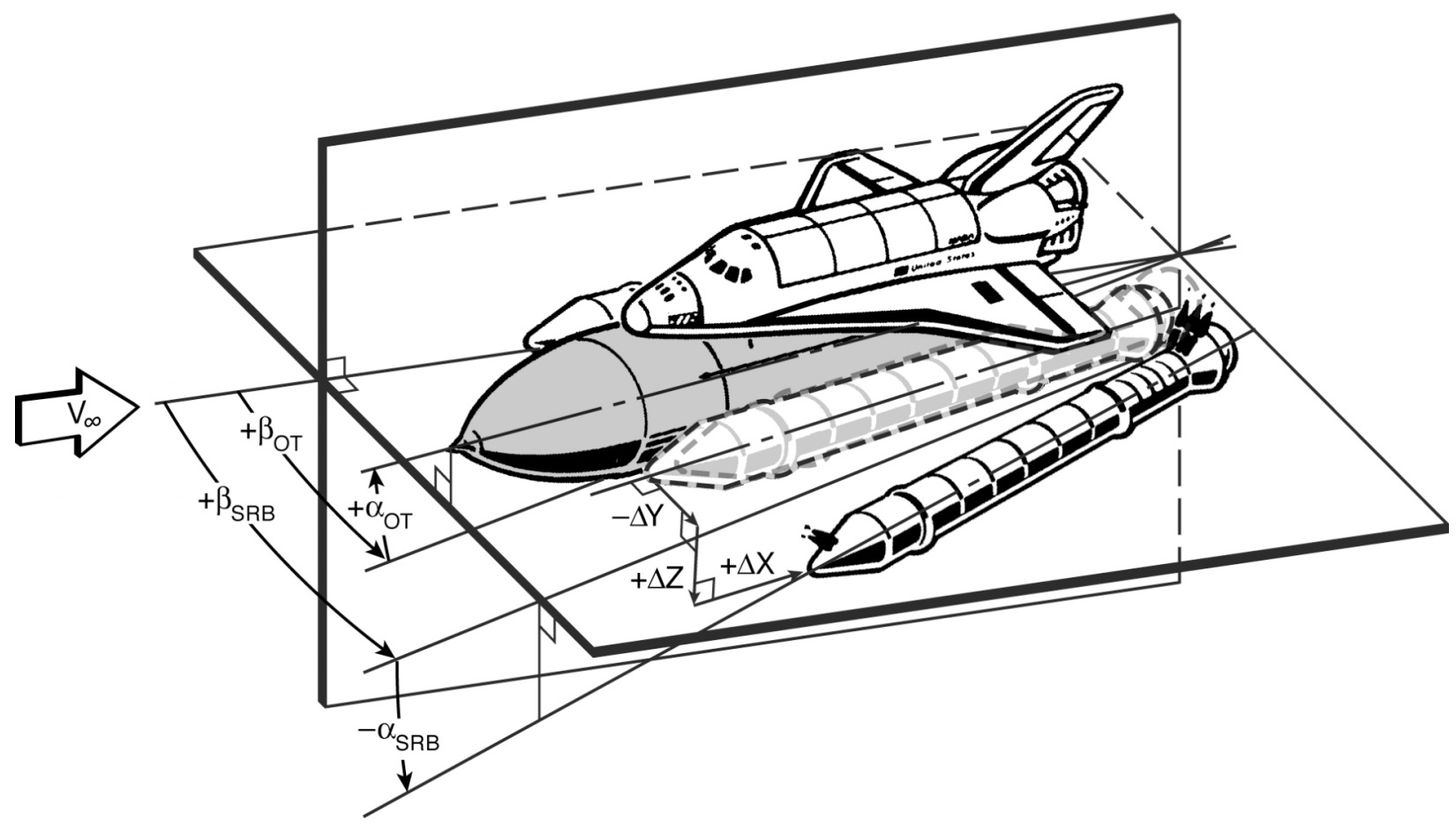

Figure 3. Relative locations of vehicles and sign conventions for IA193 wind tunnel tests and proximity aerodynamic database (Ref. 22,23 ). 


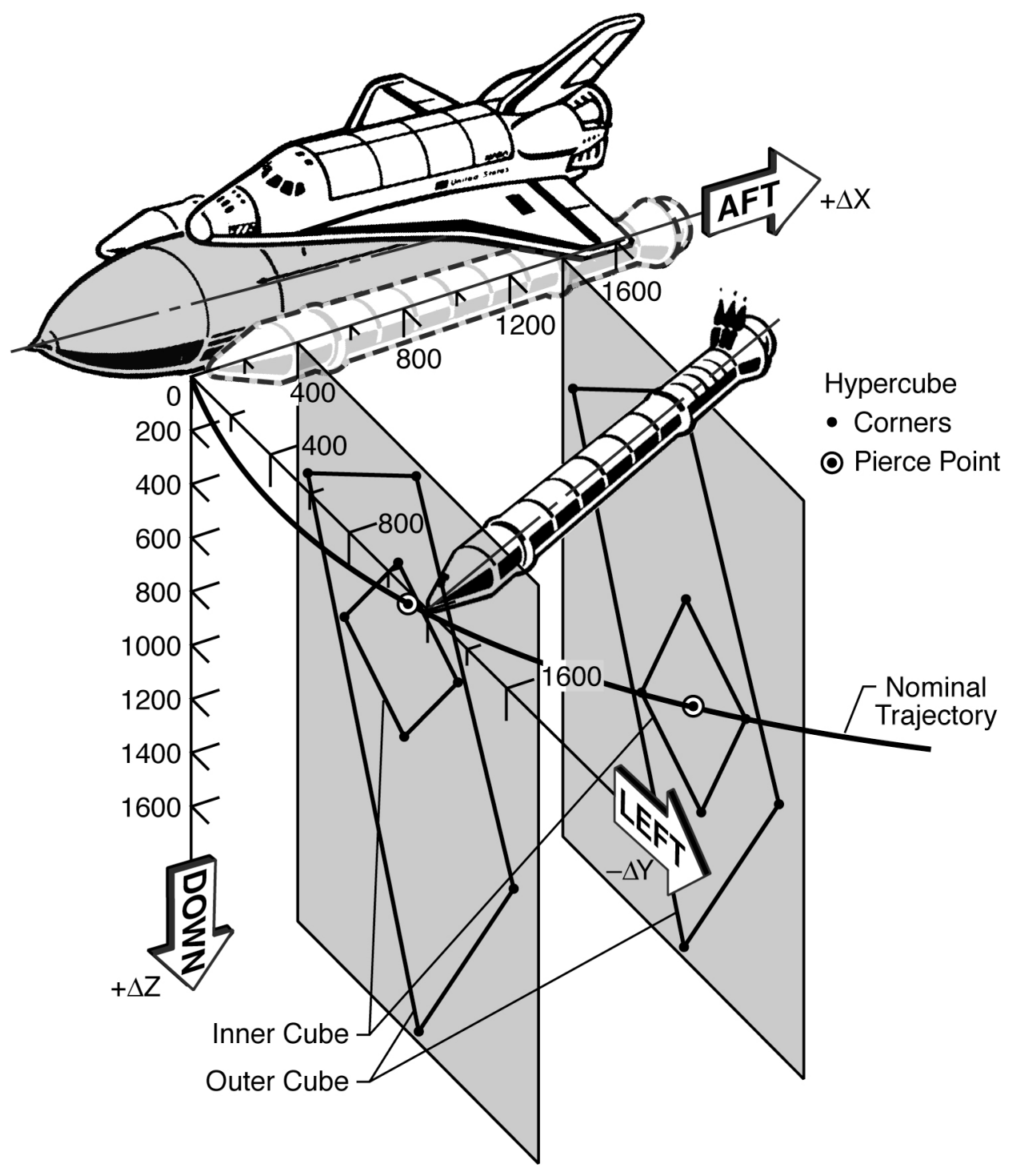

Figure 4. Hypercube data structure and nominal trajectory. 

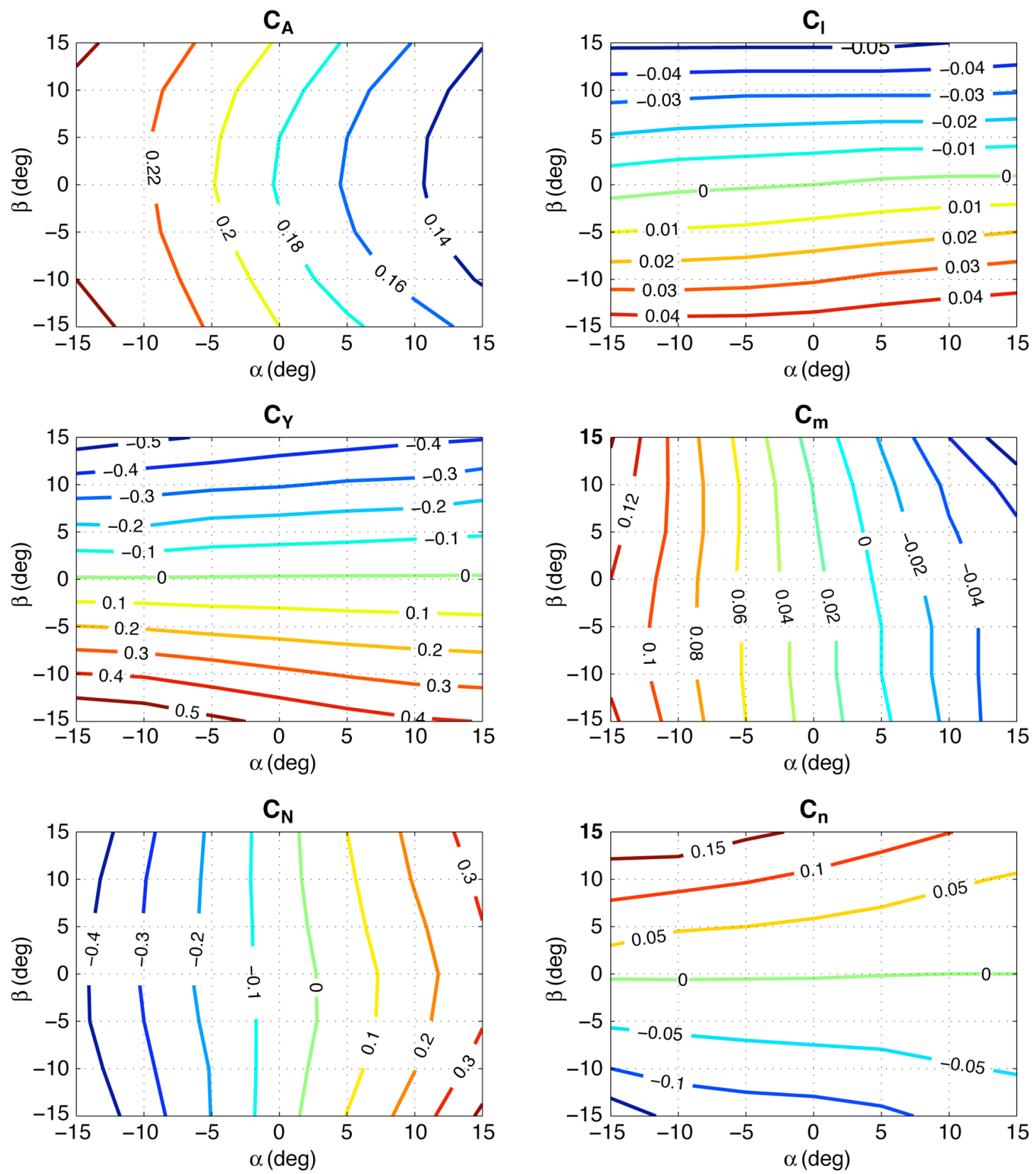

Figure 5. OET: Isolated aerodynamic coefficients at $M=4.45$. 

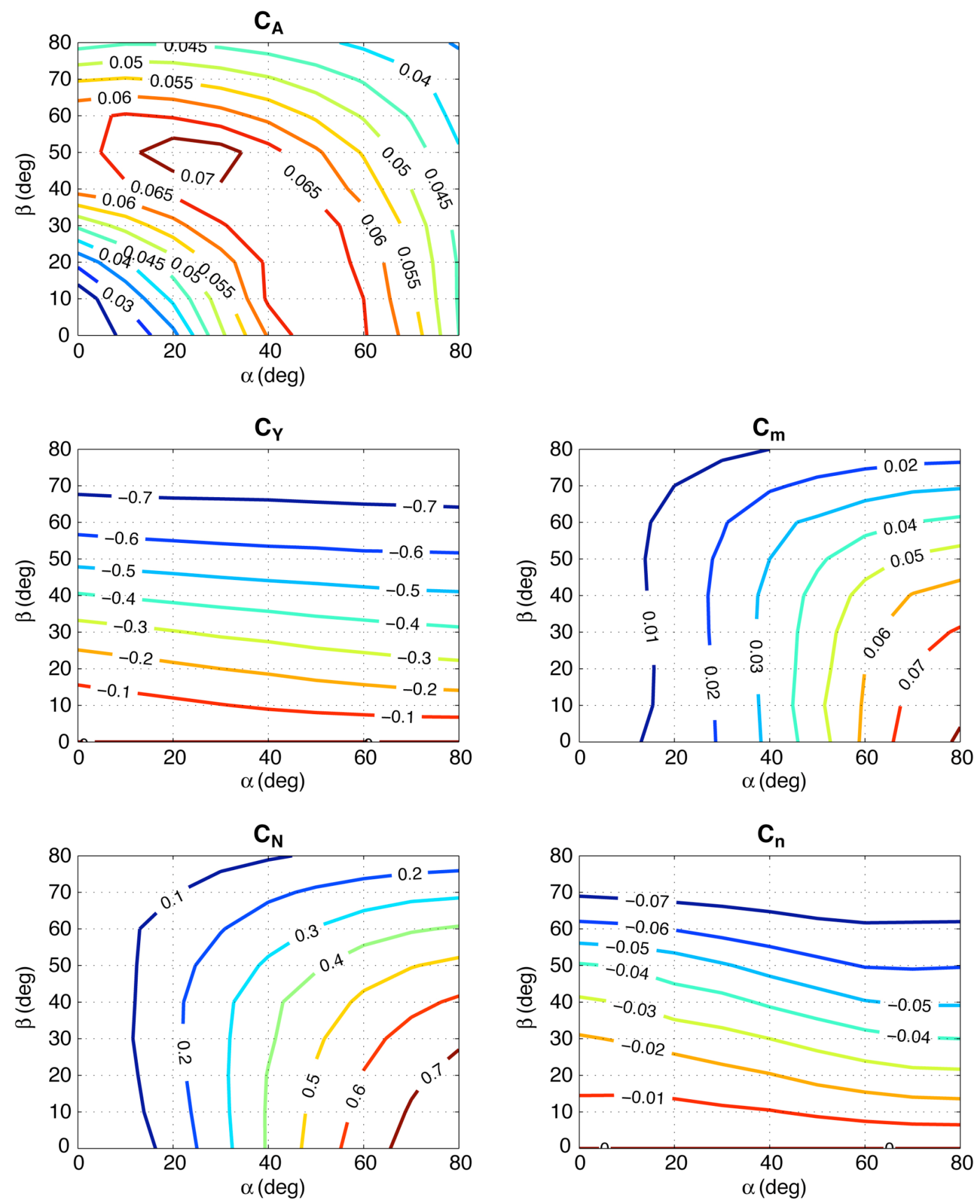

Figure 6. SRB: Isolated aerodynamic coefficients at $M=4.45$. 

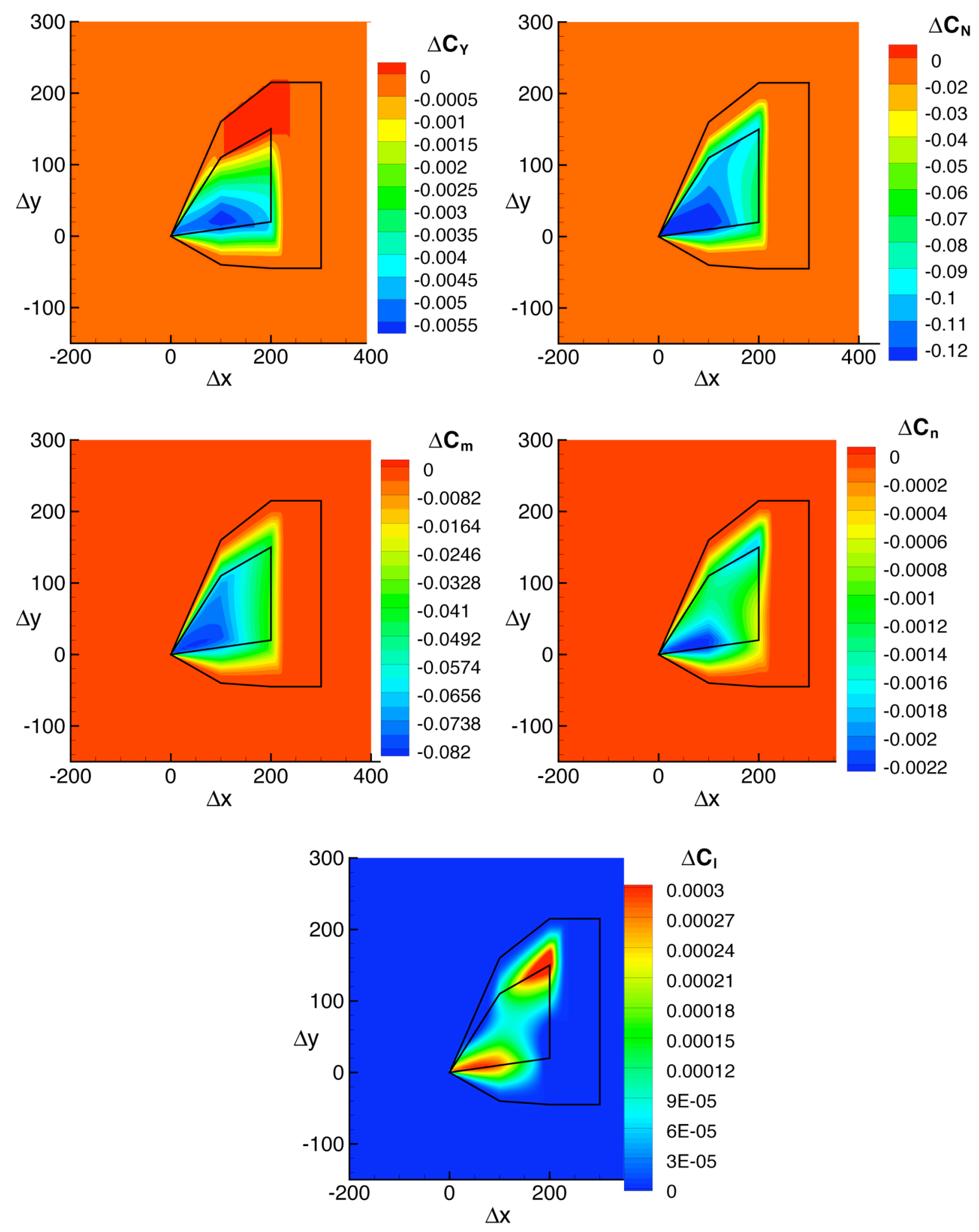

Figure 7. OET: Variation of $\Delta \mathrm{C}_{\mathrm{N}}, \Delta \mathrm{C}_{\mathrm{m}}, \Delta \mathrm{C}_{\mathrm{Y}}, \Delta \mathrm{C}_{\mathrm{l}}$, and $\Delta \mathrm{C}_{\mathrm{n}}$ with $\Delta \mathrm{x}$ and $\Delta \mathrm{y}$, inches $(\alpha=\beta=\Delta \alpha=\Delta \beta=\Delta z=0, M R=222.3)$. 

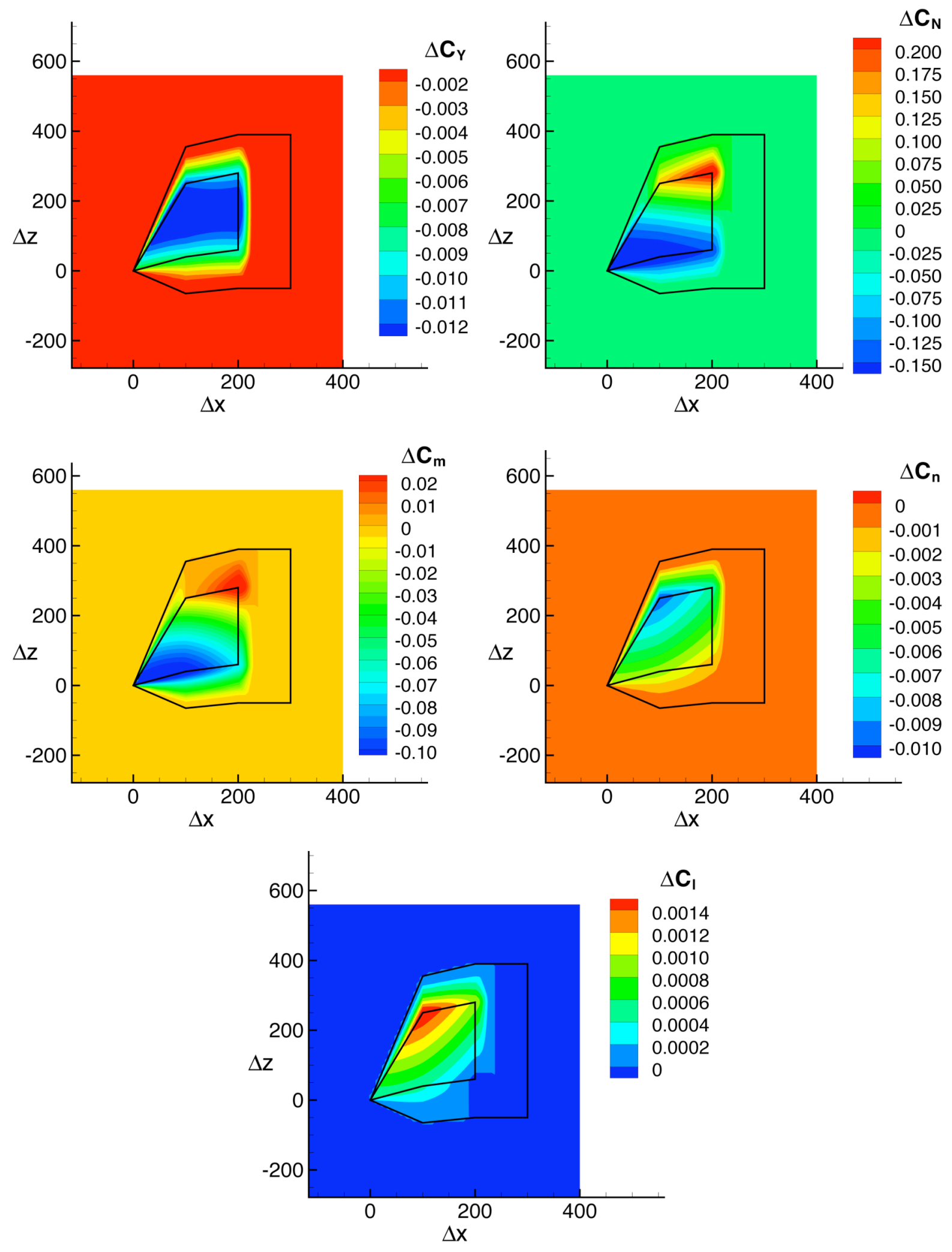

Figure 8. OET: Variation of $\Delta \mathrm{C}_{\mathrm{N}}, \Delta \mathrm{C}_{\mathrm{m}}, \Delta \mathrm{C}_{\mathrm{Y}}, \Delta \mathrm{C}_{\mathrm{l}}$, and $\Delta \mathrm{C}_{\mathrm{n}}$ with $\Delta \mathrm{x}$ and $\Delta \mathrm{z}$, inches $(\alpha=\beta=\Delta \alpha=\Delta \beta=\Delta y=0, M R=222.3)$. 

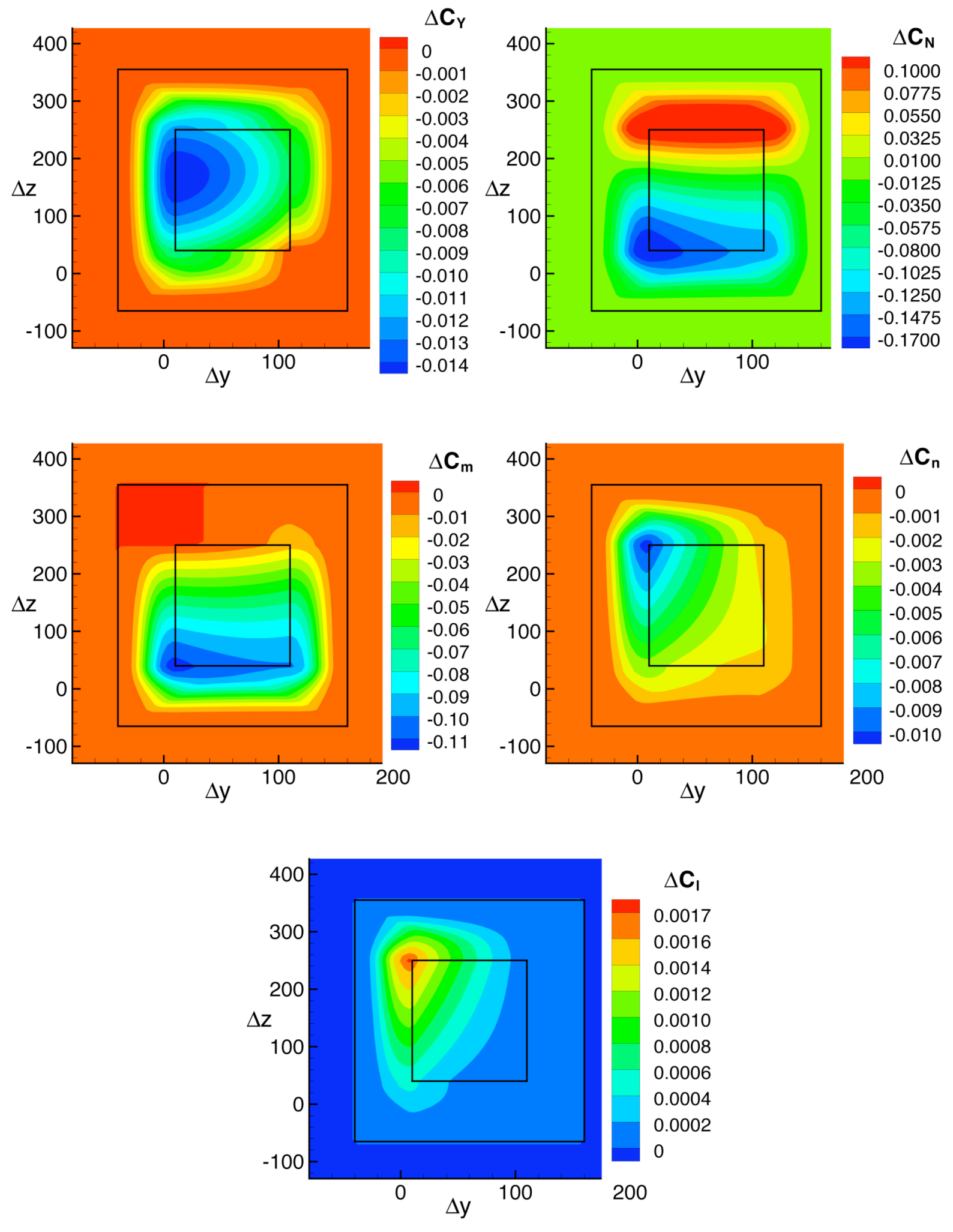

Figure 9. OET: Variation of $\Delta \mathrm{C}_{\mathrm{N}}, \Delta \mathrm{C}_{\mathrm{m}}, \Delta \mathrm{C}_{\mathrm{Y}}, \Delta \mathrm{C}_{\mathrm{l}}$, and $\Delta \mathrm{C}_{\mathrm{n}}$ with $\Delta \mathrm{y}$ and $\Delta \mathrm{z}$, inches $(\alpha=\beta=\Delta \alpha=\Delta \beta=0, \Delta x=100$ in, $M R=222.3)$. 

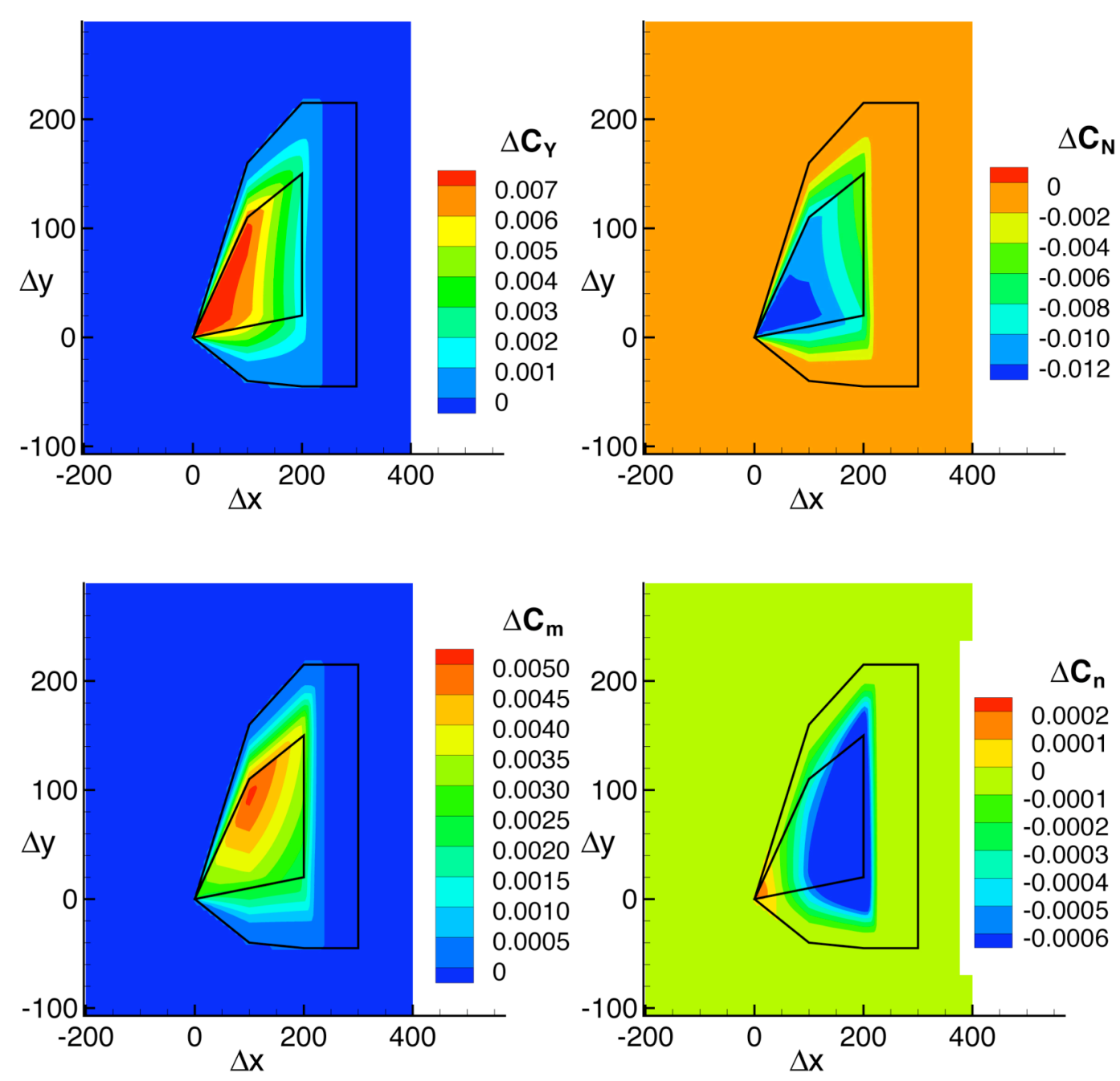

Figure 10. SRB: Variation of $\Delta \mathrm{C}_{\mathrm{N}}, \Delta \mathrm{C}_{\mathrm{m}}, \Delta \mathrm{C}_{\mathrm{Y}}$, and $\Delta \mathrm{C}_{\mathrm{n}}$ with $\Delta \mathrm{x}$ and $\Delta \mathrm{y}$, inches $(\alpha=\beta=\Delta \alpha=\Delta \beta=\Delta z=0, M R=222.3)$. 

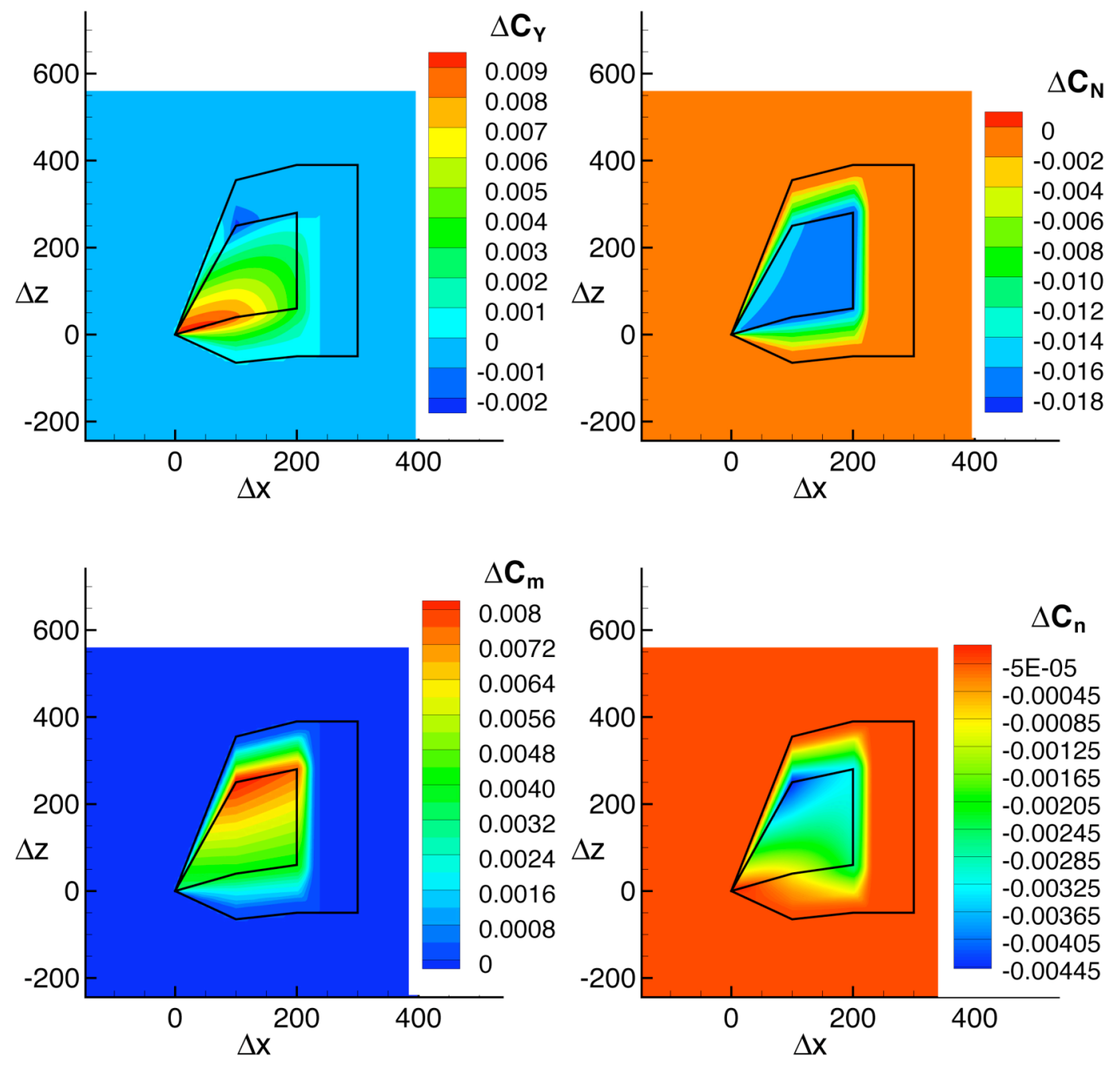

Figure 11. SRB: Variation of $\Delta \mathrm{C}_{\mathrm{N}}, \Delta \mathrm{C}_{\mathrm{m}}, \Delta \mathrm{C}_{\mathrm{Y}}$, and $\Delta \mathrm{C}_{\mathrm{n}}$ with $\Delta \mathrm{x}$ and $\Delta \mathrm{z}$, inches $(\alpha=\beta=\Delta \alpha=\Delta \beta=\Delta y=0, M R=222.3)$. 

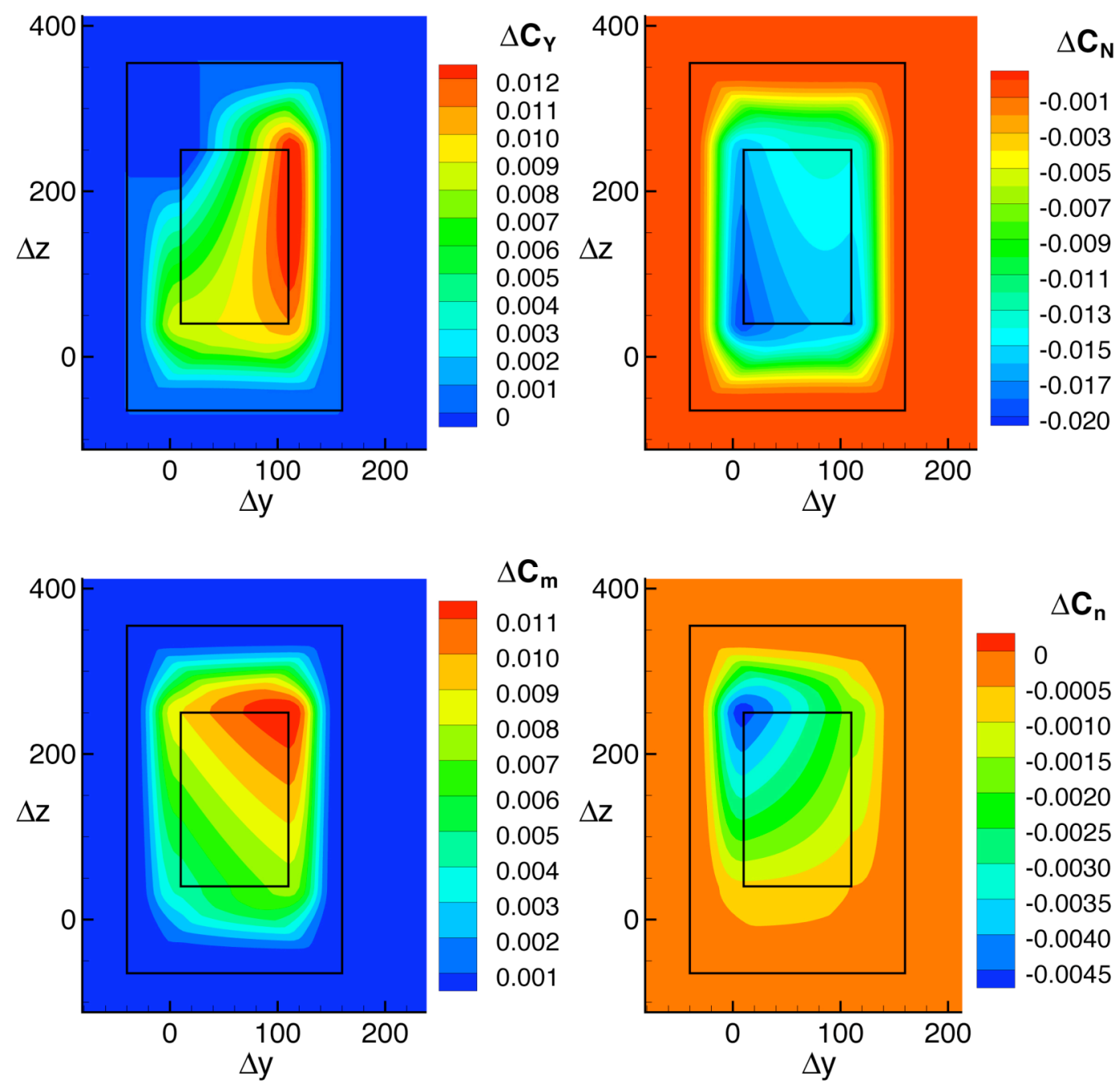

Figure 12. SRB: Variation of $\Delta \mathrm{C}_{\mathrm{N}}, \Delta \mathrm{C}_{\mathrm{m}}, \Delta \mathrm{C}_{\mathrm{Y}}$ and $\Delta \mathrm{C}_{\mathrm{n}}$ with $\Delta \mathrm{y}$ and $\Delta \mathrm{z}$, inches $(\alpha=\beta=\Delta \alpha=\Delta \beta=0, \Delta x=100$ in, $M R=222.3)$. 


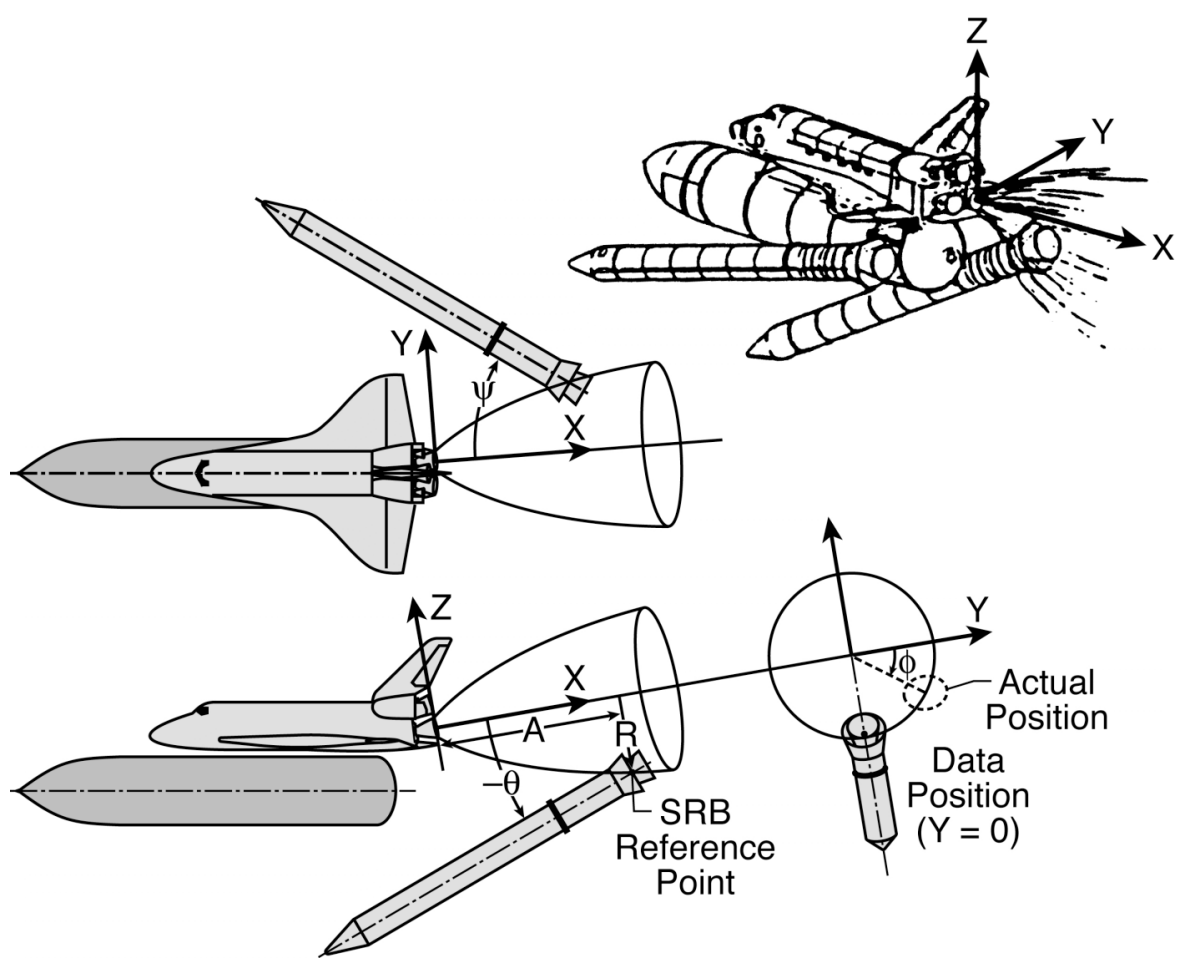

Figure 13. Schematic illustration SSME plume impingement coordinate system (Ref. 19). 


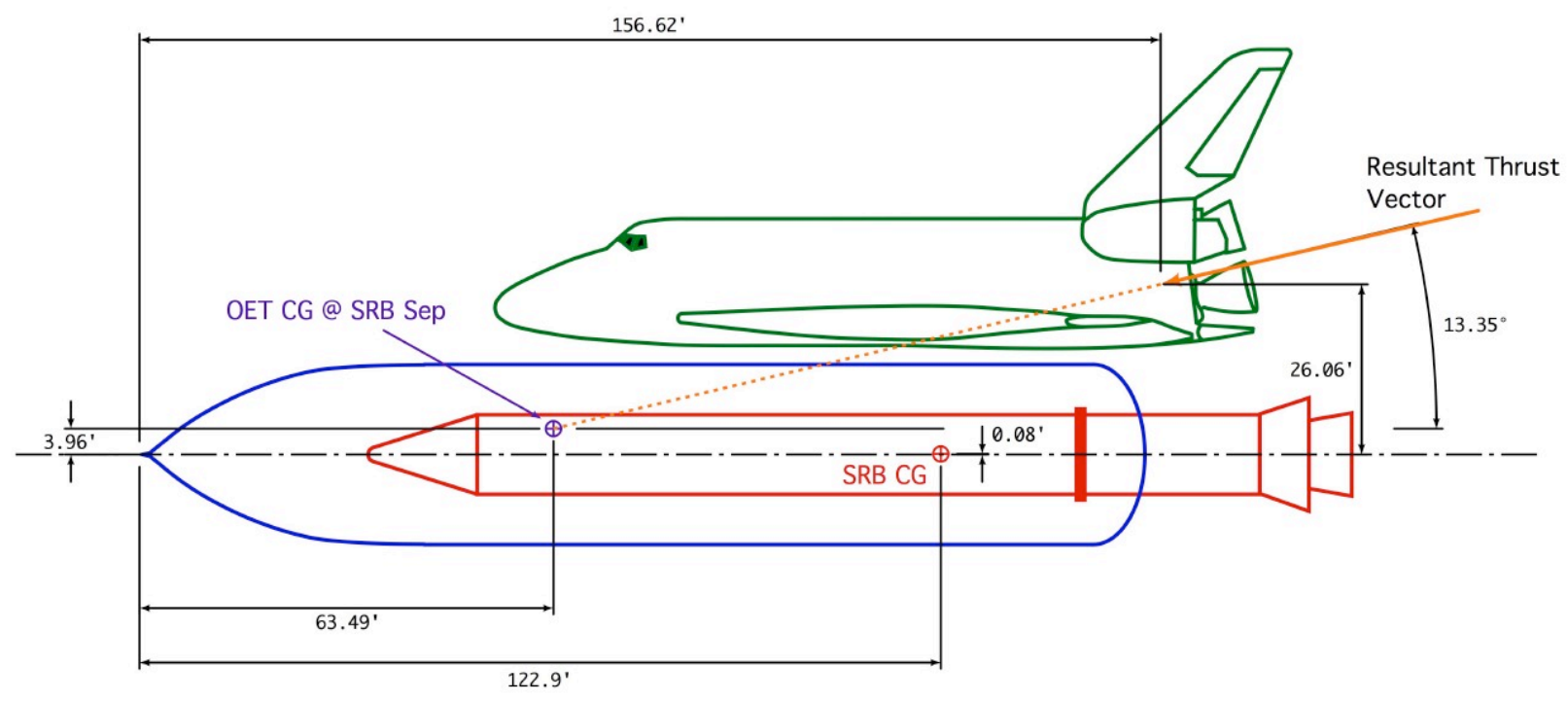

Figure 14. Center of gravity locations at SRB separation for STS-1.

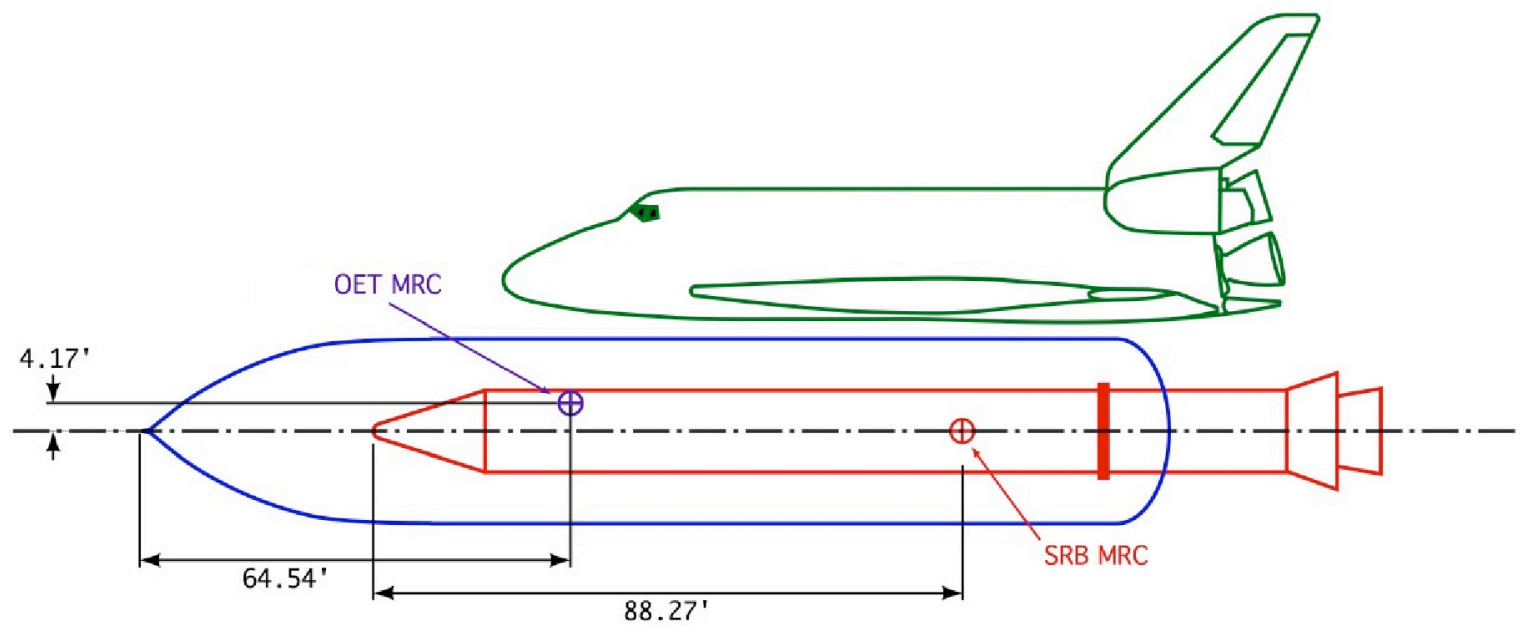

Figure 15. Locations of aerodynamic moment reference points. 


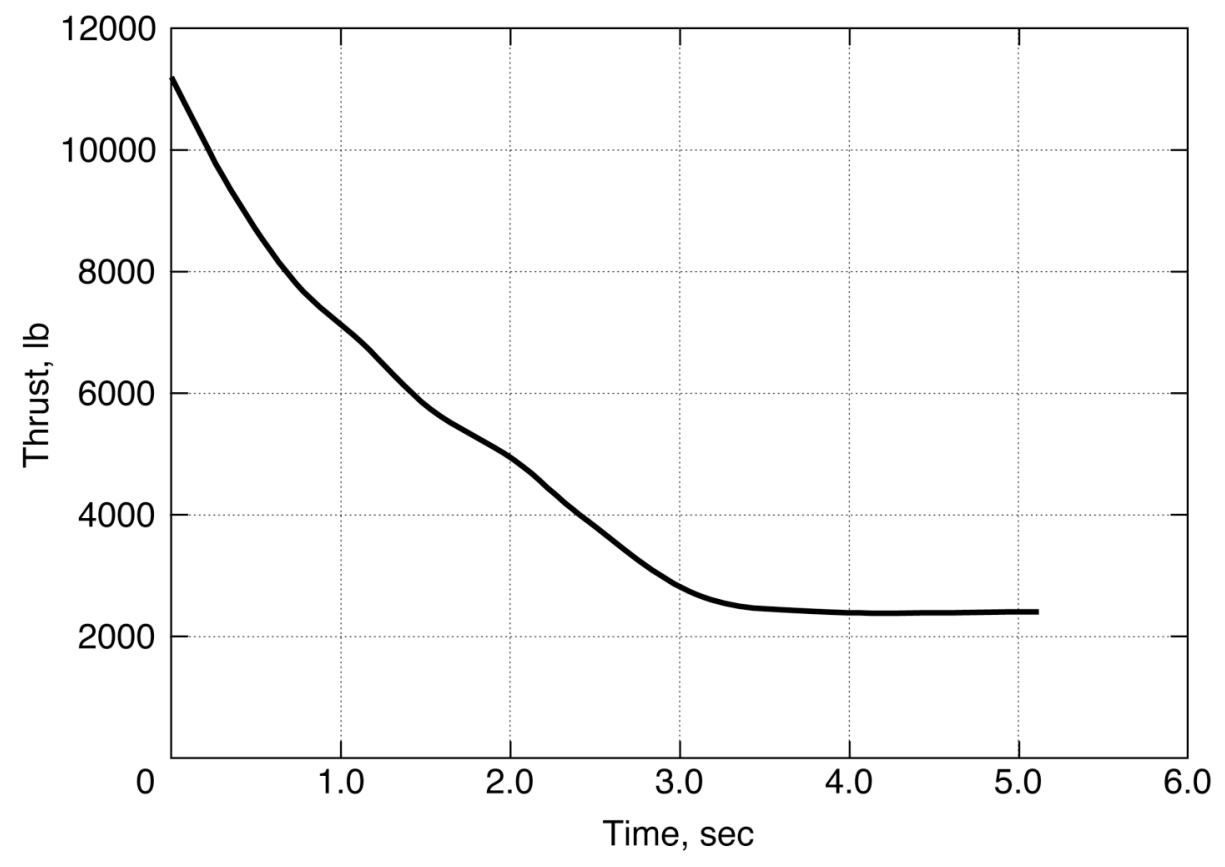

Figure 16. SRB thrust tail-off characteristics for STS-1.

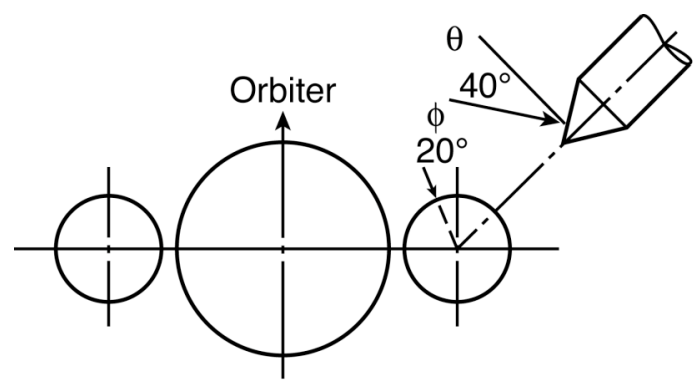

Forward View Looking Aft

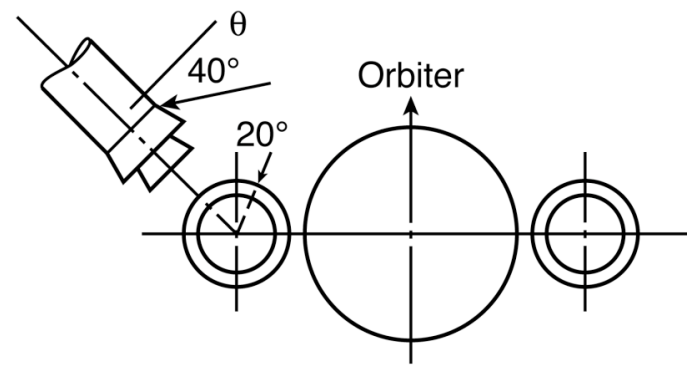

Aft View Looking Forward

Figure 17. BSM cluster locations and orientations. 


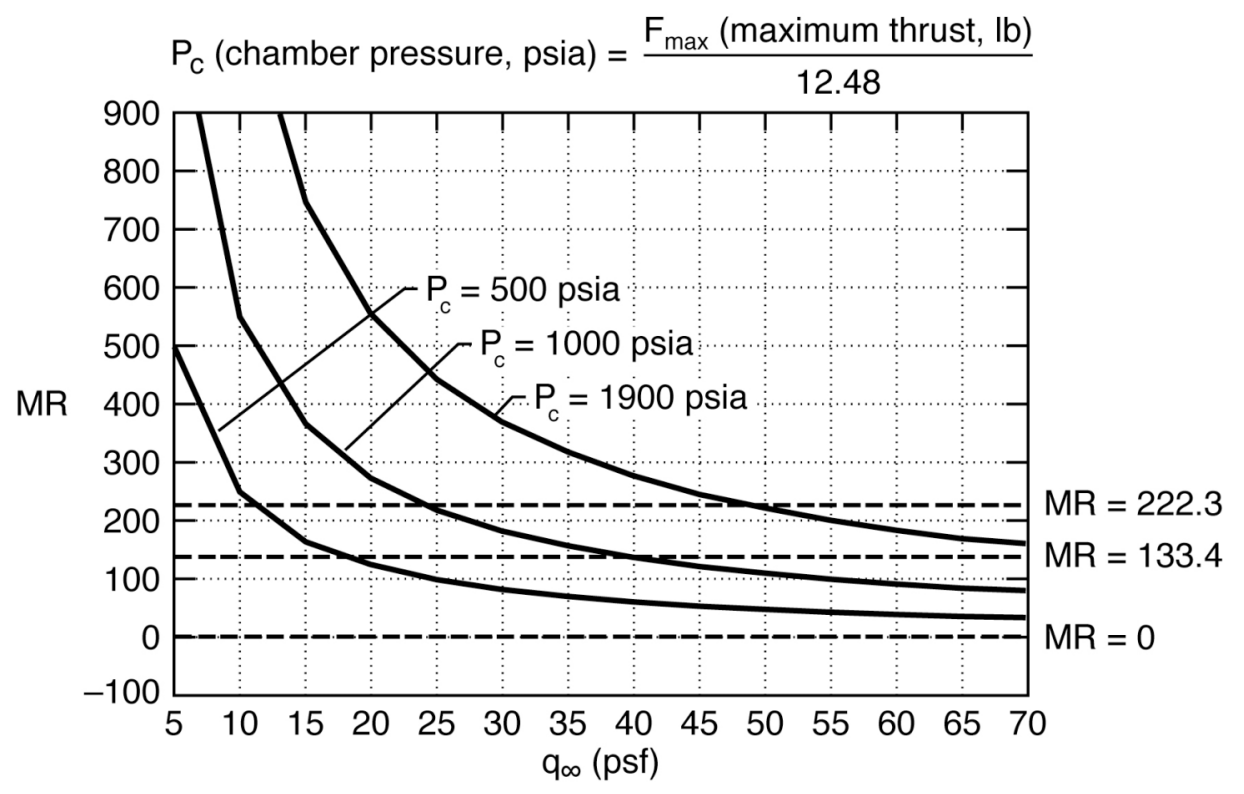

Figure 18. Variation of BSM jet momentum ratio with freestream dynamic pressure (Ref. 20).

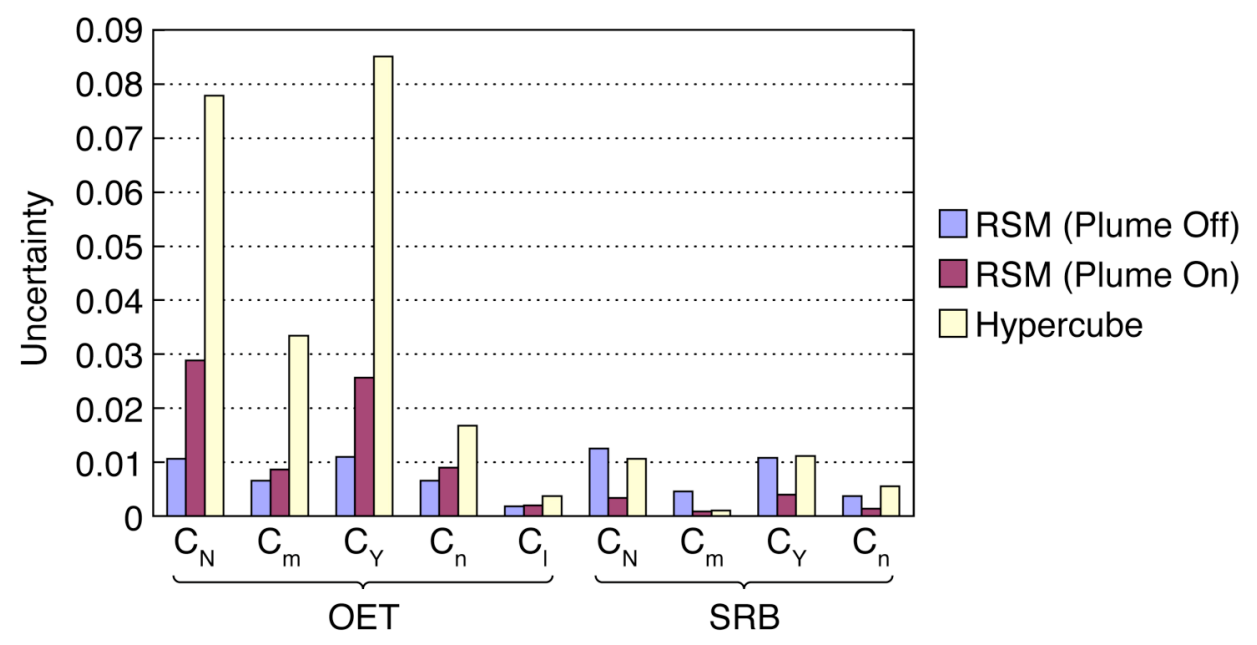

Figure 19. Comparison of uncertainty in proximity aerodynamic coefficients. 


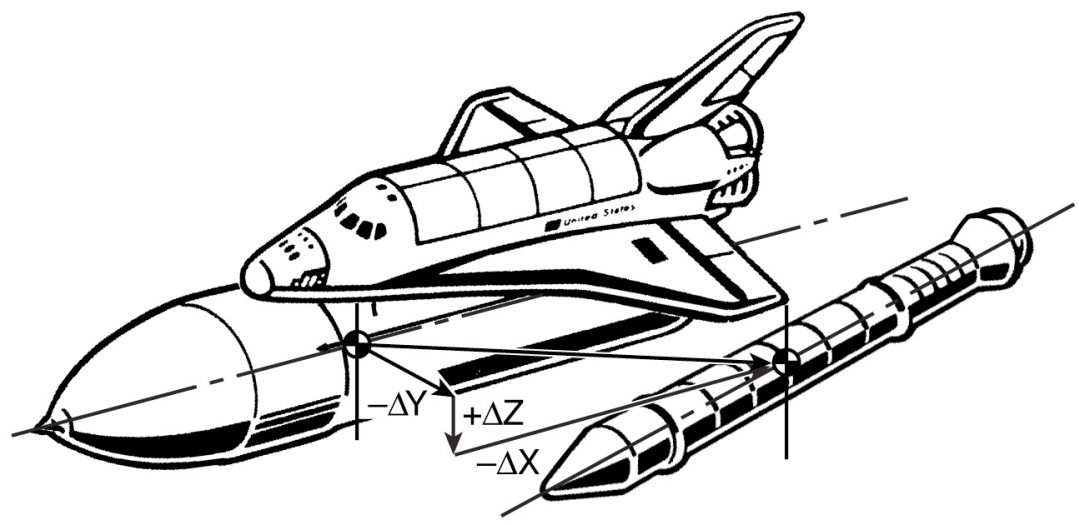

Figure 20. Definition of relative motion parameters for STS-1 flight data. 

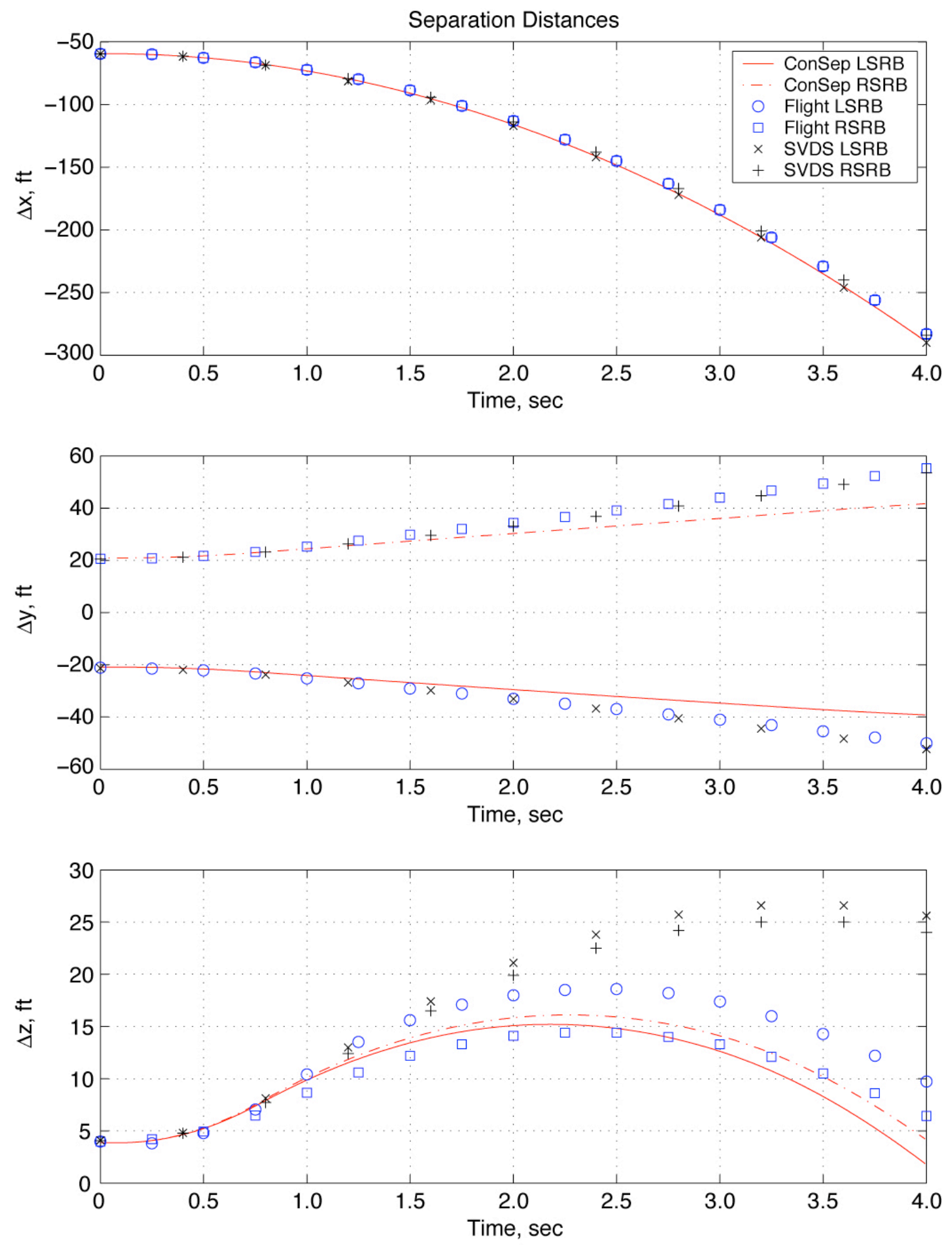

Figure 21. Variation of relative distances $\Delta \mathrm{x}, \Delta \mathrm{y}$ and $\Delta \mathrm{z}$ with time during SRB separation, STS-1. 

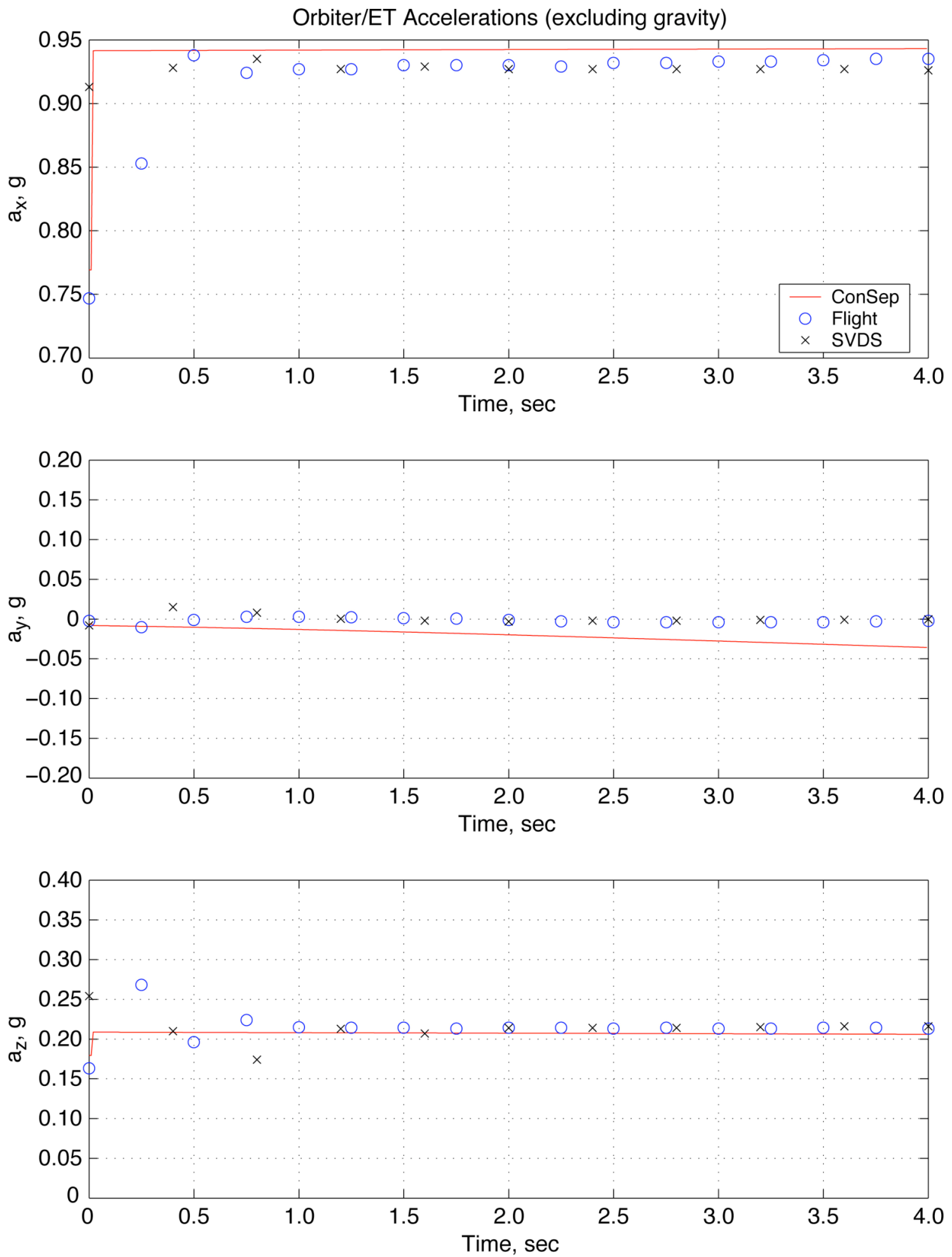

Figure 22. OET: Variation of acceleration components during separation, STS-1. 

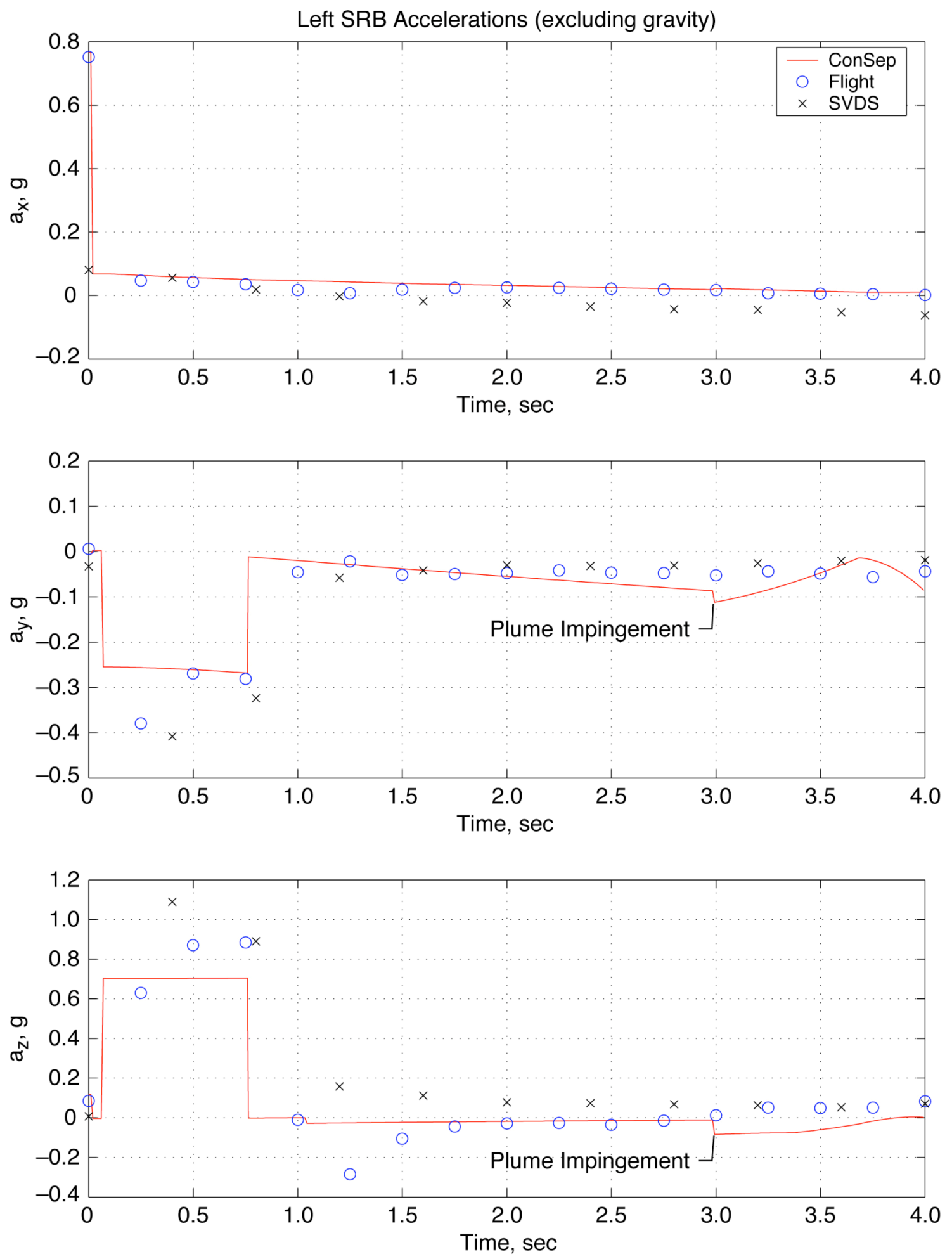

Figure 23. Left SRB: Variation of acceleration components during separation, STS-1. 

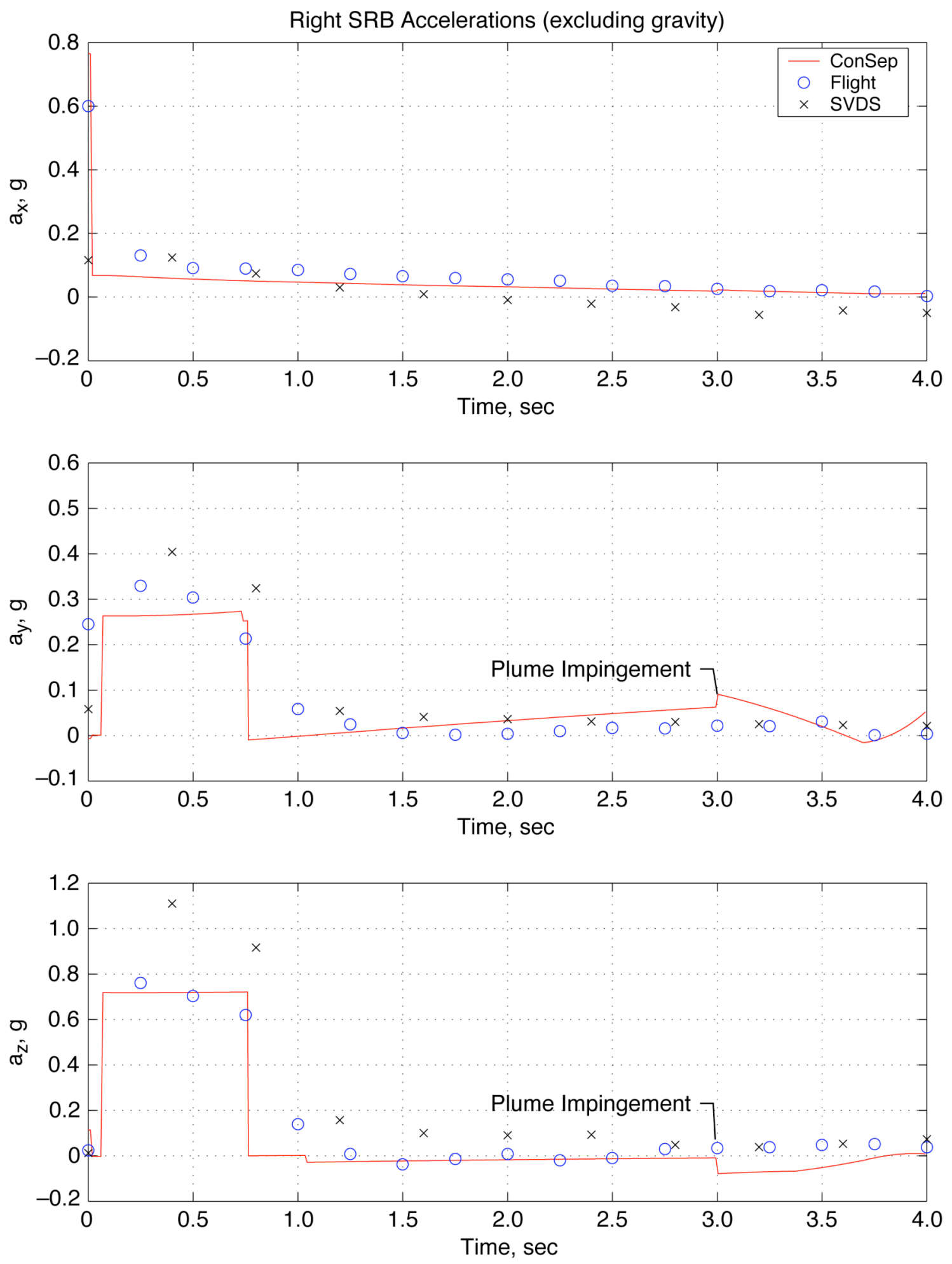

Figure 24. Right SRB: Variation of acceleration components during separation, STS-1. 

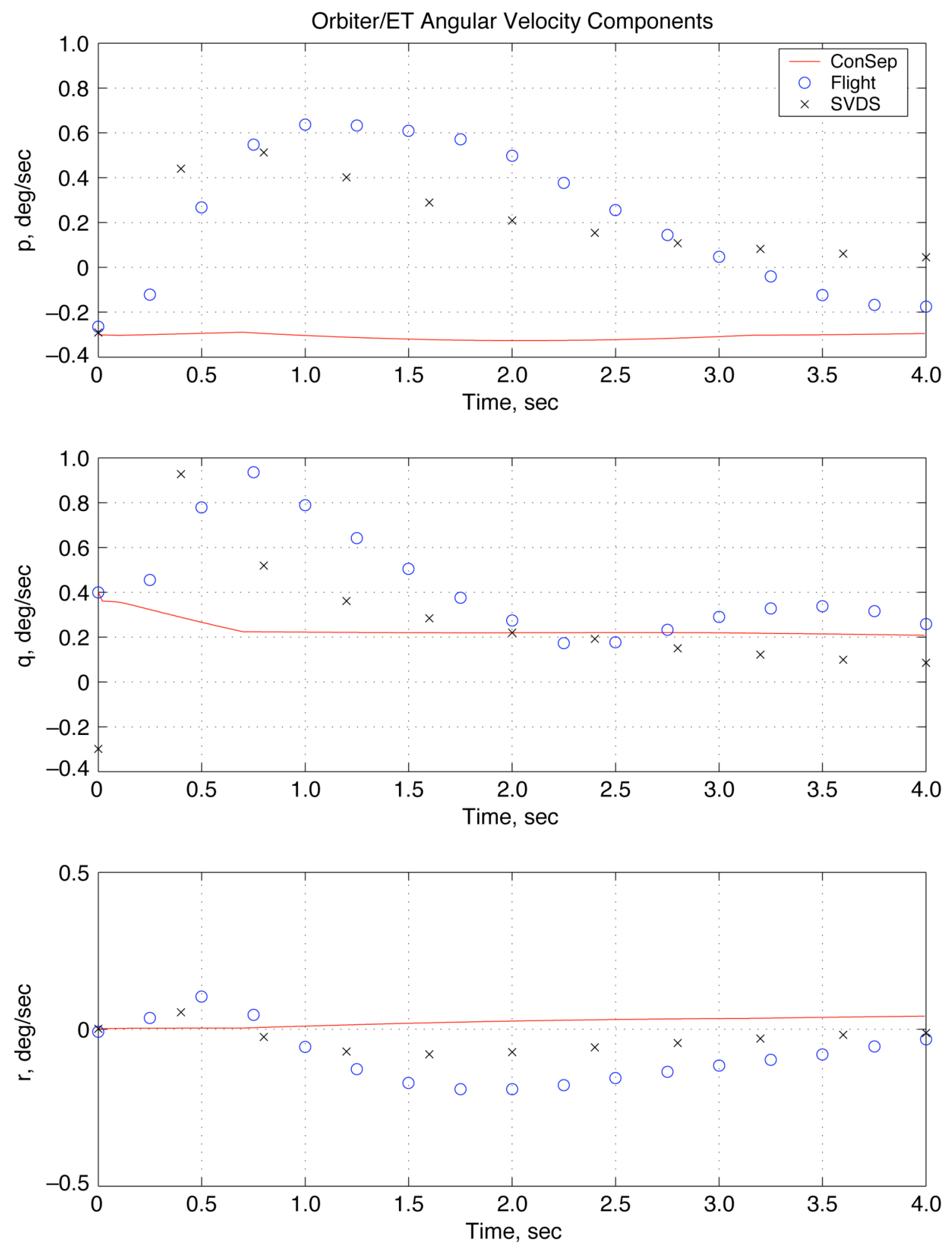

Figure 25. OET: Variation of angular velocity components during separation, STS-1. 

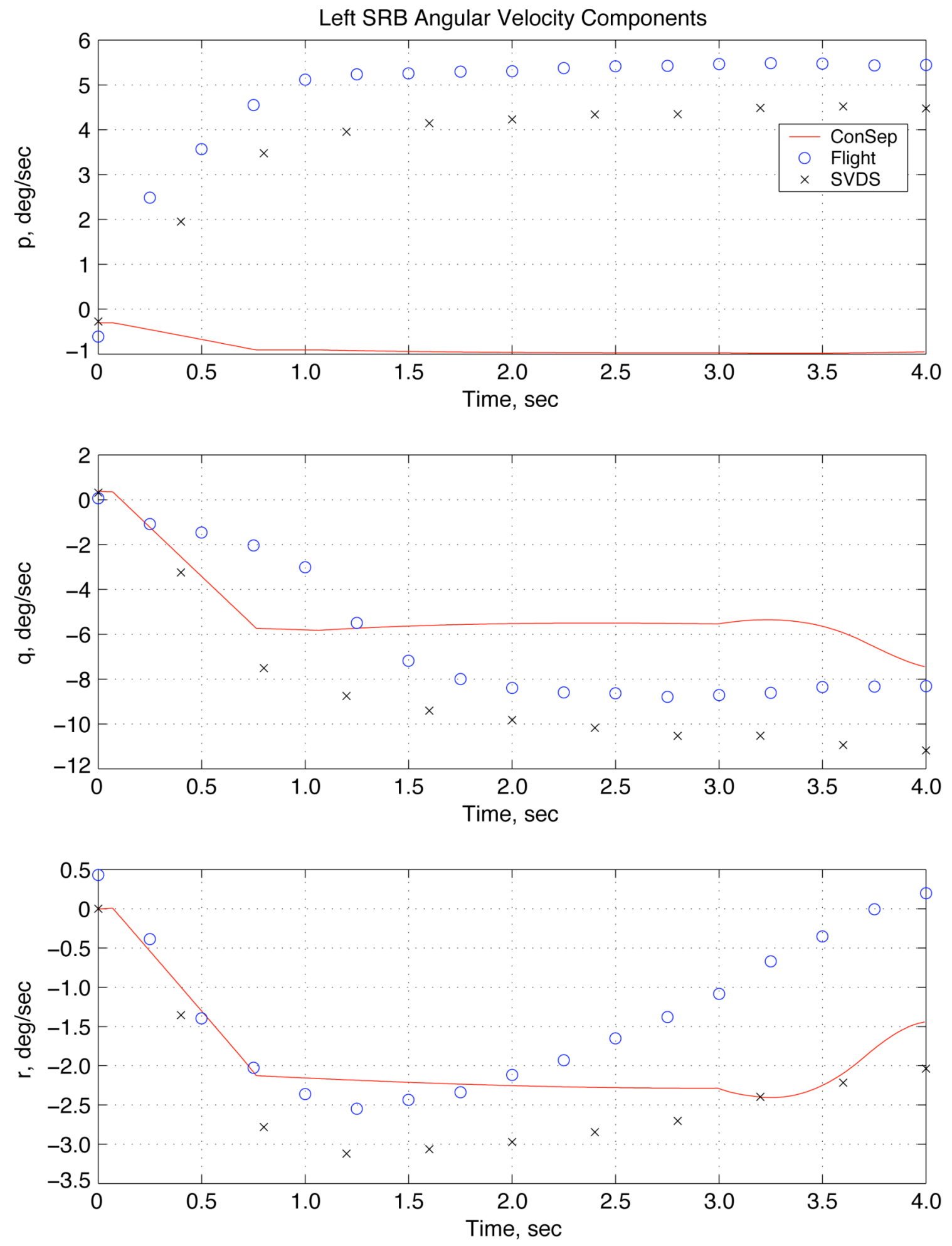

Figure 26. Left SRB: Angular velocity components during separation, STS-1. 
Right SRB Angular Velocity Components
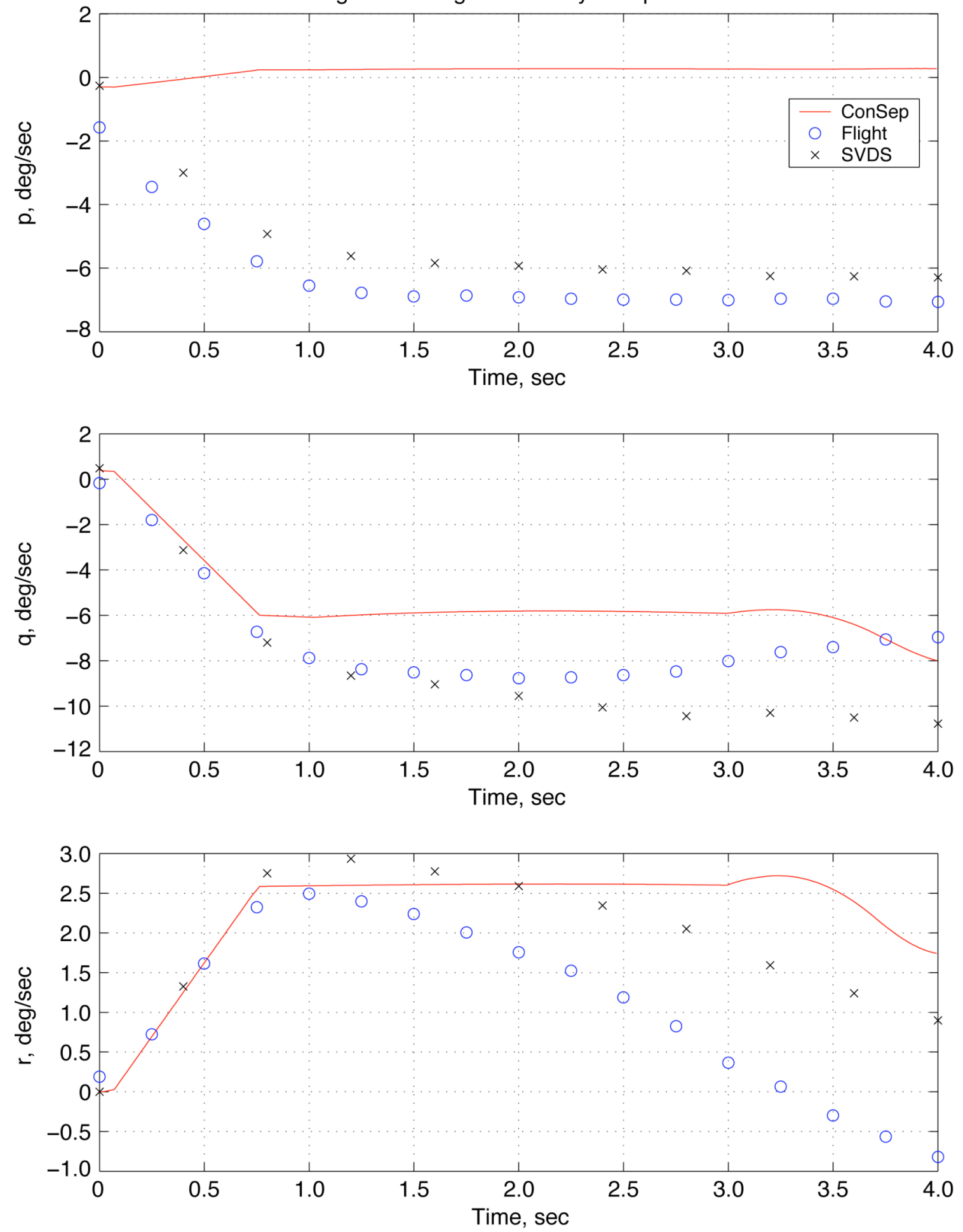

Figure 27. Right SRB: Angular velocity components during separation, STS-1. 

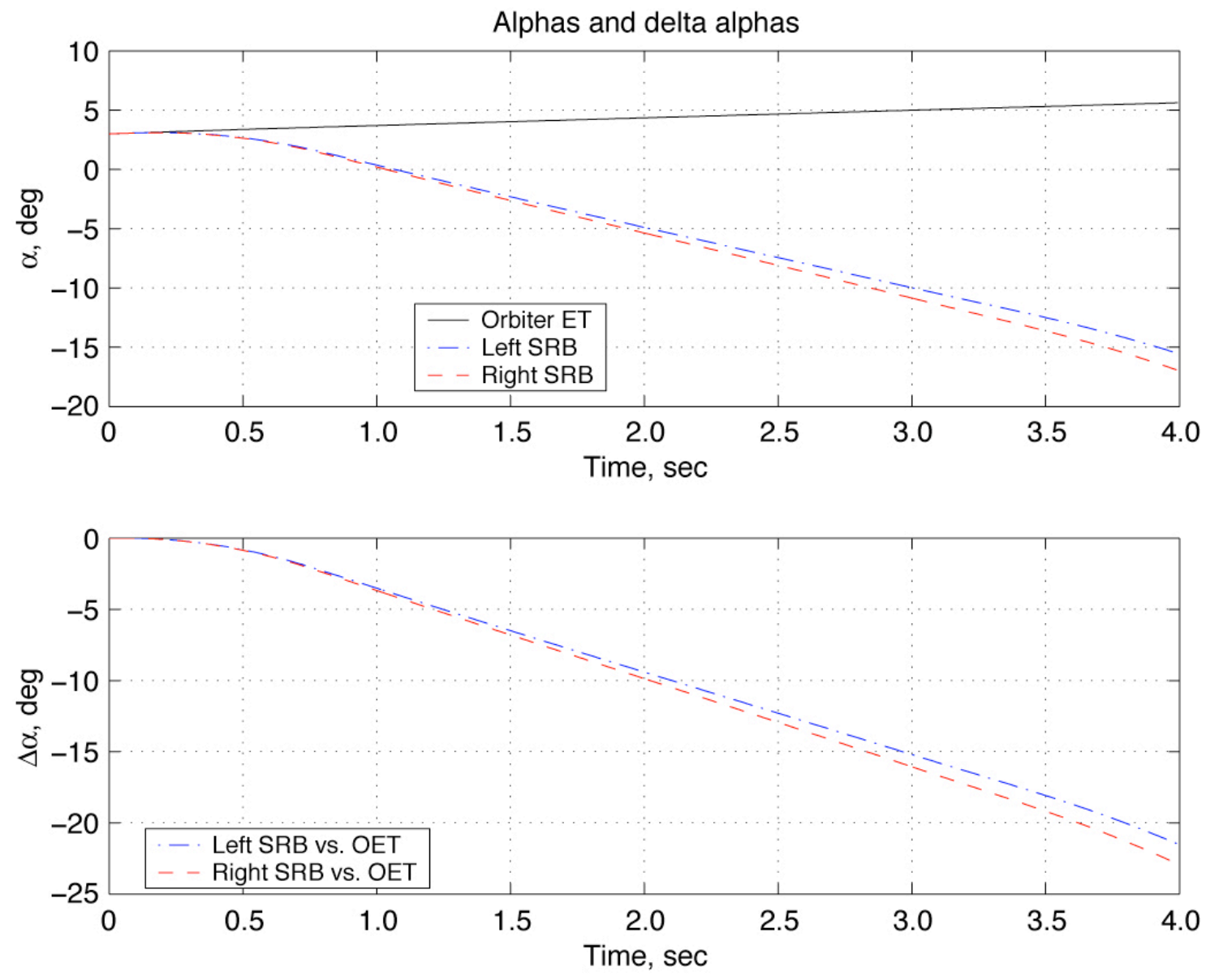

Figure 28. Angles of attack and relatives angles of attack during separation, STS-1. 

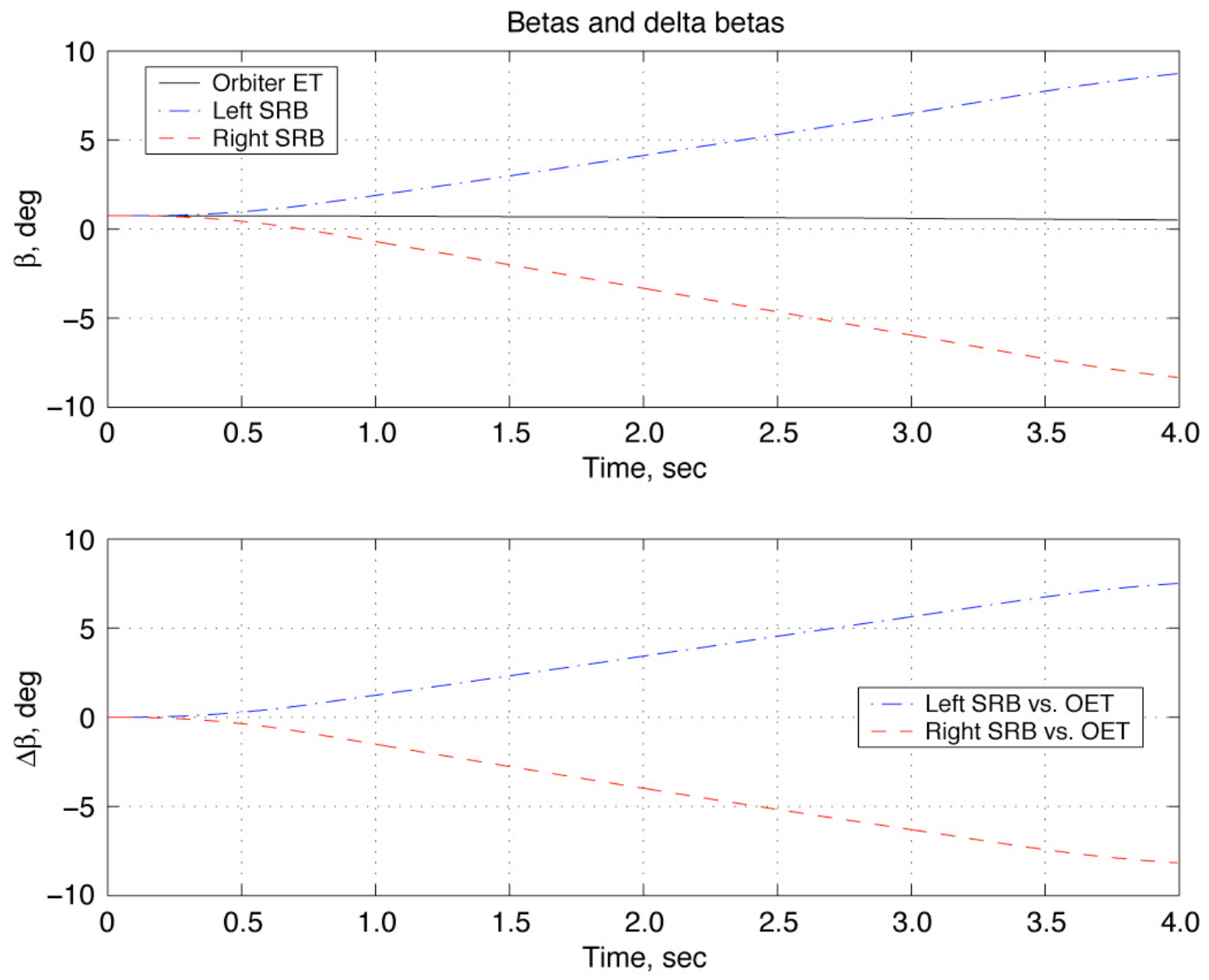

Figure 29. Sideslip and relative sideslip during ConSep simulation for SRB separation in STS-1. 


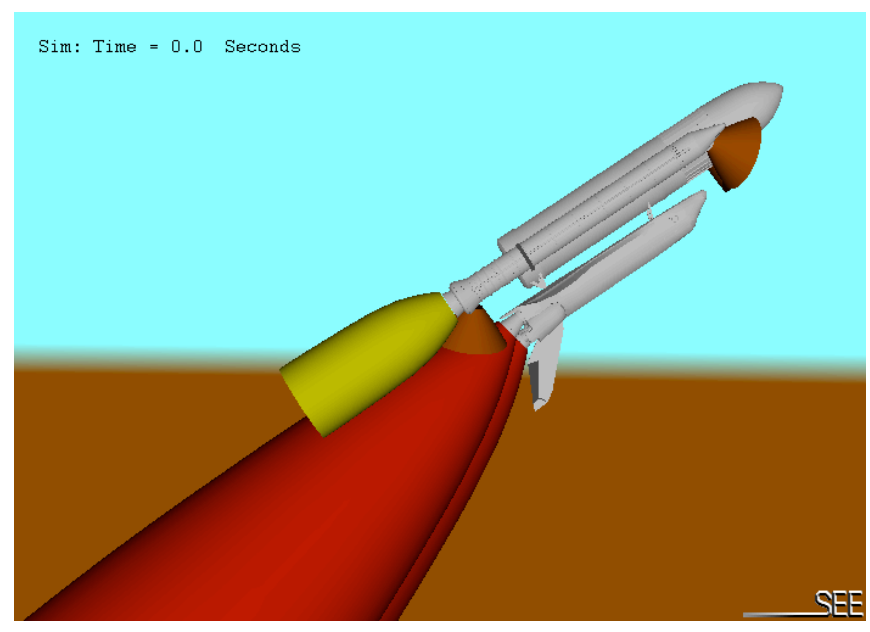

(a) $\mathbf{t}=\mathbf{0}$.

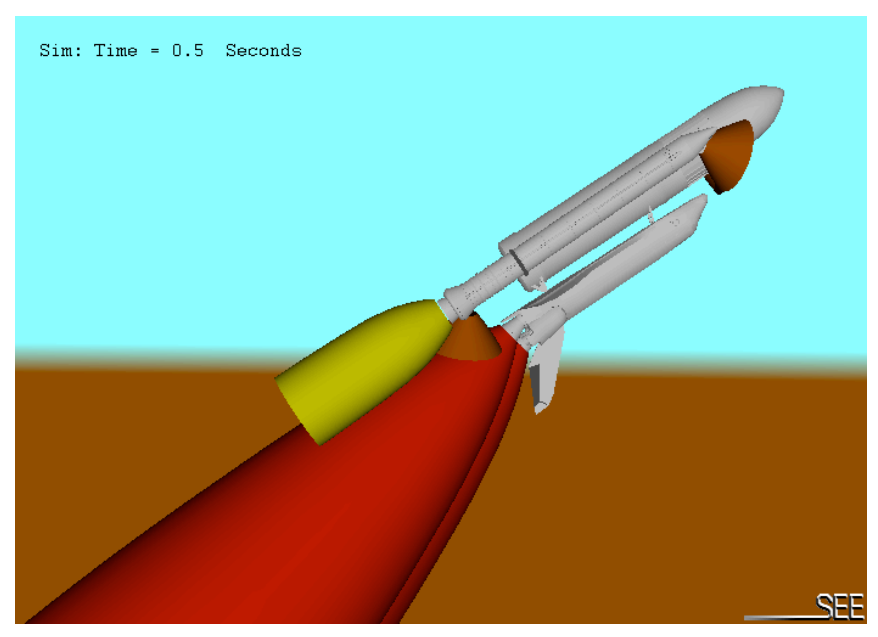

(b) $\mathrm{t}=0.5 \mathrm{sec}$.

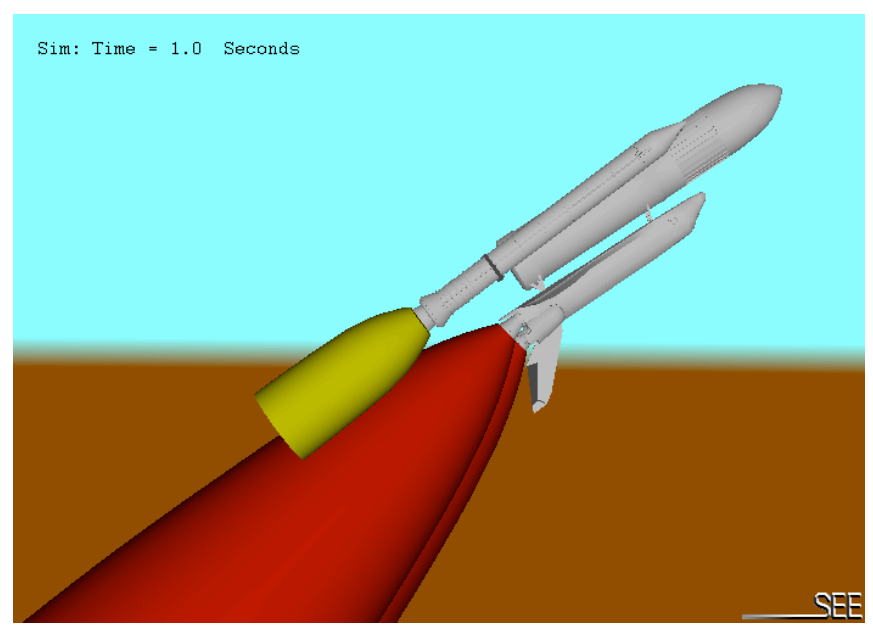

(c) $\mathbf{t}=\mathbf{1 . 0}$ sec.

Figure 30. Snap shots of ConSep simulation using SEE animation for STS-1. 


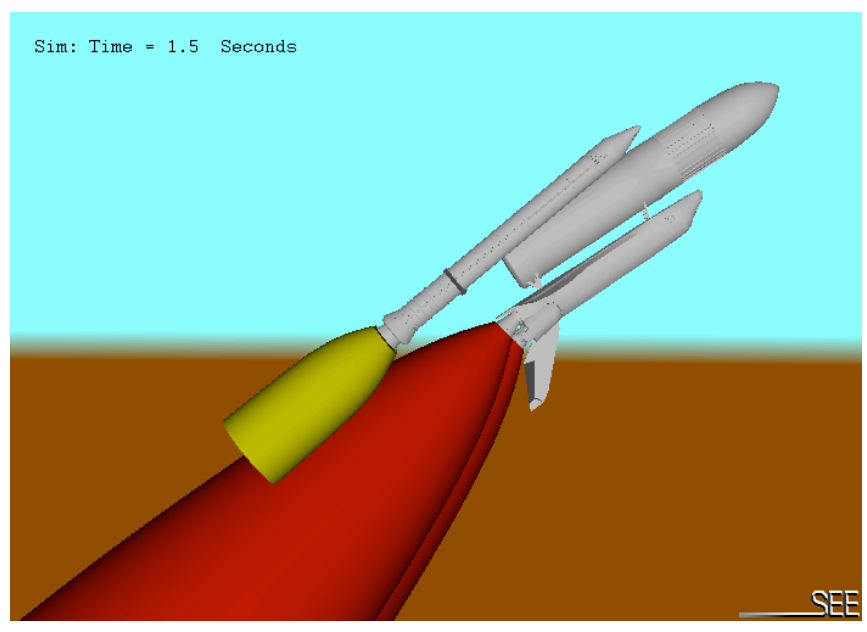

(d) $\mathbf{t}=\mathbf{1 . 5}$ sec.

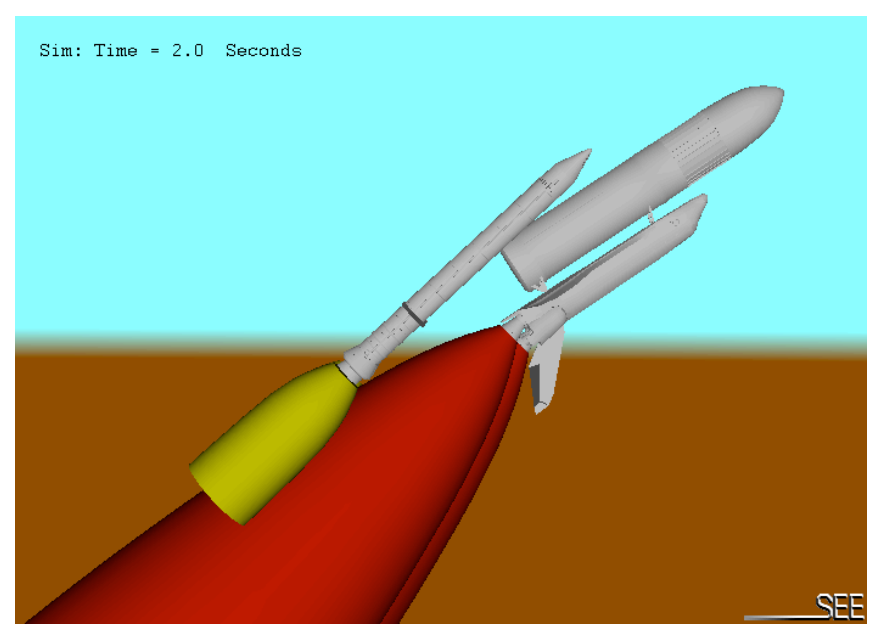

(e) $\mathrm{t}=\mathbf{2 . 0}$ sec.

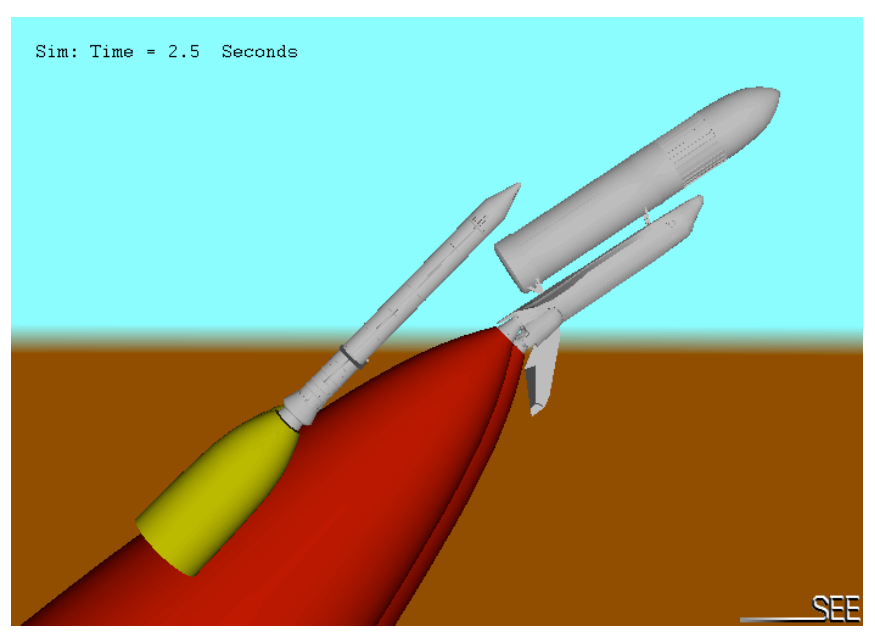

(f) $\mathrm{t}=2.5 \mathrm{sec}$.

Figure 30. Continued. 


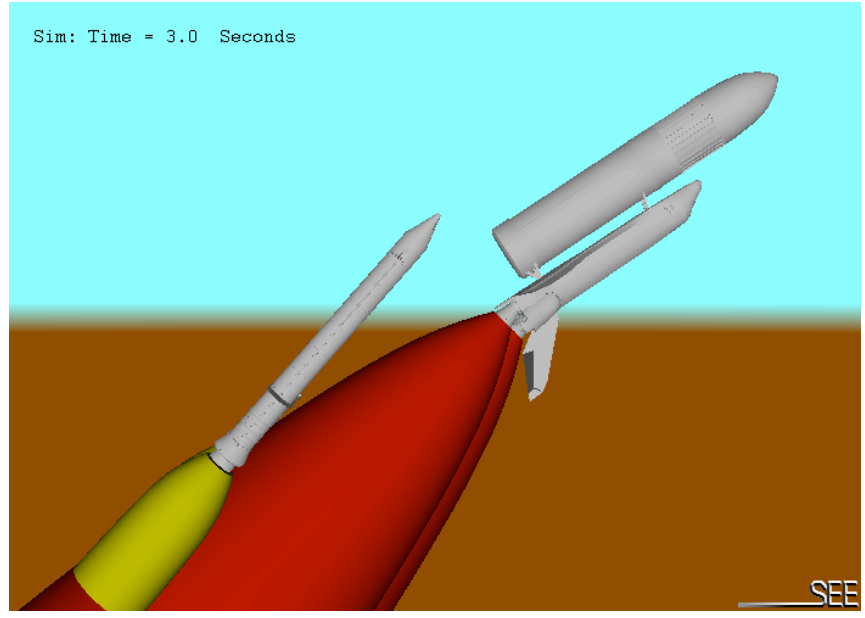

(g) $t=3.0$ sec.

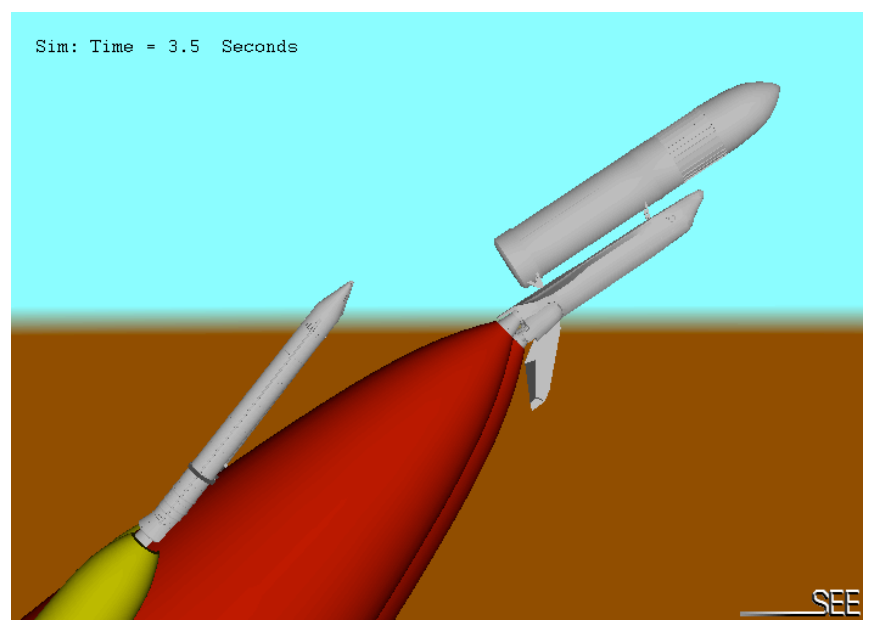

(h) $\mathrm{t}=3.5$ sec.

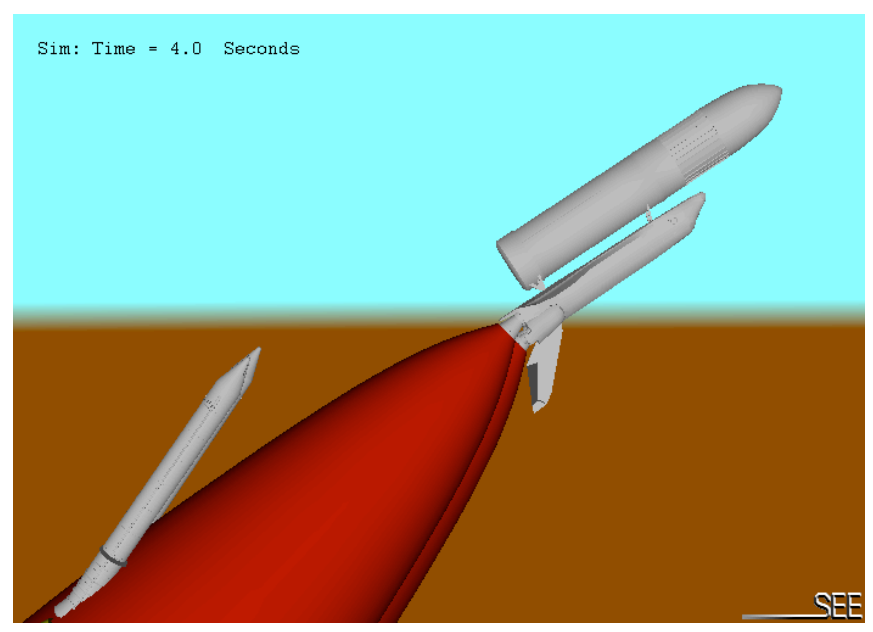

(i) $\mathbf{t}=4.0 \mathrm{sec}$

Figure 30. Concluded . 